\title{
Schlafens: Emerging Proteins in Cancer Cell Biology
}

\author{
Sarmad Al-Marsoummi ${ }^{1}$ (D), Emilie E. Vomhof-DeKrey ${ }^{1,2}$ (D) and Marc D. Basson ${ }^{1,2,3, *(D)}$ \\ 1 Department of Biomedical Sciences, School of Medicine and the Health Sciences, University of North Dakota, \\ Grand Forks, ND 58202, USA; sarmad.al.marsoummi@ndus.edu (S.A.-M.); emilie.dekrey@und.edu (E.E.V.-D.) \\ 2 Department of Surgery, School of Medicine and the Health Sciences, University of North Dakota, \\ Grand Forks, ND 58202, USA \\ 3 Department of Pathology, School of Medicine and the Health Sciences, University of North Dakota, \\ Grand Forks, ND 58202, USA \\ * Correspondence: marc.basson@und.edu; Tel.: +701-777-6226
}

Citation: Al-Marsoummi, S.; Vomhof-DeKrey, E.E.; Basson, M.D. Schlafens: Emerging Proteins in Cancer Cell Biology. Cells 2021, 10, 2238. https://doi.org/10.3390/ cells10092238

Academic Editor: Lluis Espinosa

Received: 4 August 2021

Accepted: 25 August 2021

Published: 29 August 2021

Publisher's Note: MDPI stays neutral with regard to jurisdictional claims in published maps and institutional affiliations.

Copyright: (c) 2021 by the authors. Licensee MDPI, Basel, Switzerland. This article is an open access article distributed under the terms and conditions of the Creative Commons Attribution (CC BY) license (https:// creativecommons.org/licenses/by/ $4.0 /)$.

\begin{abstract}
Schlafens (SLFN) are a family of genes widely expressed in mammals, including humans and rodents. These intriguing proteins play different roles in regulating cell proliferation, cell differentiation, immune cell growth and maturation, and inhibiting viral replication. The emerging evidence is implicating Schlafens in cancer biology and chemosensitivity. Although Schlafens share common domains and a high degree of homology, different Schlafens act differently. In particular, they show specific and occasionally opposing effects in some cancer types. This review will briefly summarize the history, structure, and non-malignant biological functions of Schlafens. The roles of human and mouse Schlafens in different cancer types will then be outlined. Finally, we will discuss the implication of Schlafens in the anti-tumor effect of interferons and the use of Schlafens as predictors of chemosensitivity.
\end{abstract}

Keywords: Schlafen; cancer; signaling; differentiation; invasion; proliferation; immune response

\section{Introduction}

The Schlafens (SLFN) are a novel and poorly understood family of proteins that have chiefly been investigated for their potential roles in non-malignant cell differentiation, cell proliferation, and the immune response. However, these proteins are now increasingly believed to be important in cancer. This review will briefly summarize basic Schlafen protein biology and then outline current knowledge about the role of Schlafen proteins in cancer.

Schlafens were first discovered in mice in 1998 by Schwarz et al. [1], describing the murine proteins Slfn1, Slfn2, Slfn3, and Slfn4. These proteins have subsequently been shown to be expressed in a wide range of vertebrates, including humans [2]. Mouse Slfn1 was the first discovered Schlafen and was reported to induce thymocyte cell cycle arrest (put the cell to sleep), thereby giving rise to the name of this class of proteins from the German word "Schlafen", which means "sleep" [1]. Later, in 2000, Slfn2 was connected to Dickkopf-1 protein (DKK1) lethality in mice [3]. In 2004, Geserick et al. [4] identified and characterized another subgroup of Schlafens in mice characterized by a C-terminal sequence motif homologous to the superfamily I of DNA/RNA helicases and were identified as Slfn5, Slfn8, Slfn9, Slfn10, and Slfn14. In 2009, genomic and phylogenetic studies conducted by Bustos et al. [5] showed that Schlafens are widely expressed in mammals and identified the Schlafen genes in humans and other mammals.

Mice express ten Schlafens. These are Slfn1, Slfn1L, Slfn2, Slfn3, Slfn4, Slfn5, Slfn8, Slfn9, Slfn10 pseudogene, and Slfn14. In comparison, humans express six Schlafens. These are SLFN5, SLFN11, SLFN12, SLFN12L, SLFN13, and SLFN14 [2,6]. Schlafen genes are located on chromosome 17 in humans, while in mice they localize to chromosome 11 [2,6] (Figure 1). 


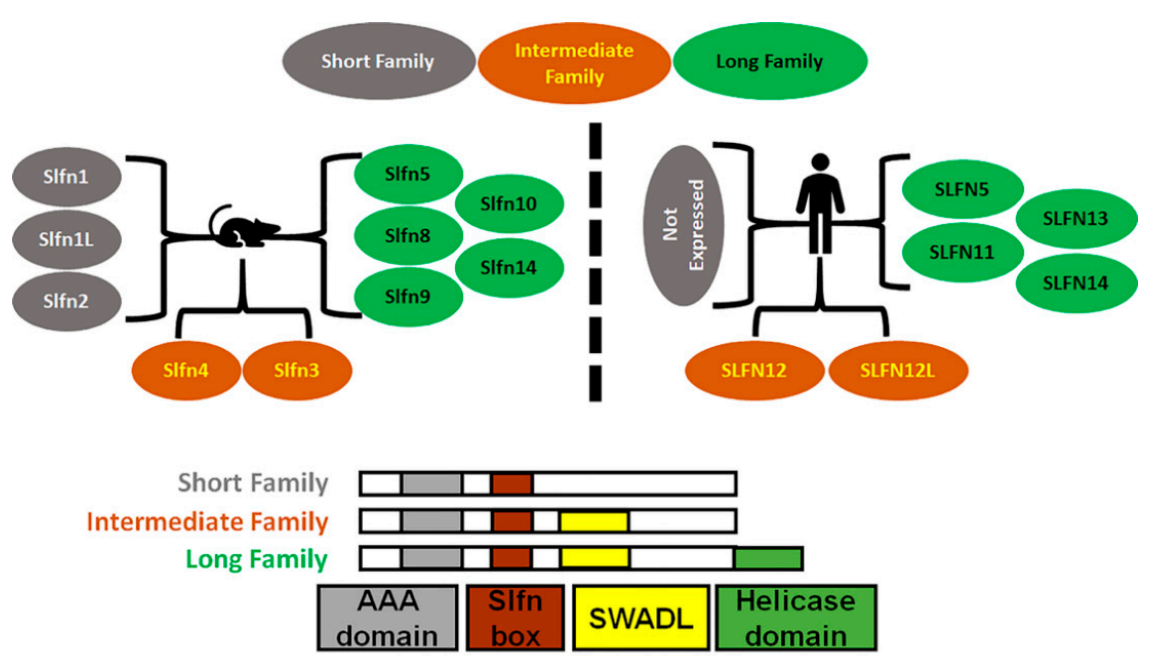

Figure 1. Diagrammatic representation of Schlafens family in mice and humans. Schlafens are classified into three families: short (grey), intermediate (orange), and long (green). Humans do not express short family Schlafens. All Schlafens share the SLFN box and putative AAA domains, while the SWADL domain is found in only intermediate and long Schlafens. Long Schlafens have an extra C-terminal helicase domain that harbors a nuclear targeting sequence.

SLFN5/Slfn5 and SLFN14/Slfn14 are the only direct orthologs between humans and mice. However, Slfn3 and Slfn4 share significant homology with SLFN12 and SLFN12L and have therefore also been identified as their orthologs [7]. Phylogenic analysis suggests Slfn8, Slfn9, and Slfn10 are orthologs to SLFN13, but there is no evidence or functional study that confirms a mouse ortholog of SLFN11.

Schlafens are expressed in diverse mammals, as well as in frogs and elephant fish. However, most research has focused on the role and function of Schlafens in mice, humans, and some viruses that express a viral ortholog of Schlafen identified as v-slfn. Schlafens were initially demonstrated to be differentially expressed in lymphoid tissue and thus believed to play a role in the maturation and activation of thymocytes [1]. However, further exploration has extended our understanding of Schlafen function to include roles in cell proliferation [8,9], cell differentiation [10,11], viral replication [12,13], cancer biology [14-17], and sensitizing cancer cells to chemotherapy [18-23].

\section{Schlafen Structure}

Schlafens have a unique molecular structure with no similarities to other known proteins. Sequence homology analysis for Schlafens using the NCBI database matched only Schlafens or unidentified proteins [24]. Schlafens differ in length (ranging from 337 to 910 amino acids) and structure. They are categorized into three subgroups or families based on their molecular structure and size (Figure 1). Short Schlafens have a molecular weight between 37-42 kDa, intermediate Schlafens have a molecular weight between 58-68 kDa, and long Schlafens exhibit molecular weights of 100-104 kDa, including an extra C-terminal domain [4]. All Schlafens have a Slfn-box domain, a sequence unique to Schlafens and not found in other known proteins [2]. Schlafens also contain a divergent AAA domain [2,4] and another highly conserved domain that is specific to Schlafens, known as the "SWADL" domain (the amino acid sequence Ser-Trp-Ala-Asp-Leu). This SWADL domain of unknown function is found only in short and intermediate Schlafens [25]. Long Schlafens have an extra C-terminal domain that is homologous to the DNA/RNA helicases I family [4]. In addition, long Schlafens have a nuclear localization signal and localize to the nucleus, which suggests that they may act primarily within the nucleus $[25,26]$. However, SLFN13, a long Schlafen, lacks the nuclear localization signal and is localized to the cytoplasm [27]. Short and intermediate Schlafens lack such signal $[25,28]$ and have been reported to localize to the cytoplasm $[25,29]$. Indeed, Slfn3 retains function even when a nuclear exclusion 
sequence is added that specifically prevents its accumulation in the nucleus by accelerating transport back into the cytosol [28].

\section{Role of Schlafens in Non-Malignant Biology}

The Schlafen proteins biologic roles (outside of malignancy) have been chiefly investigated in mice and humans, with some attention to the viral Schlafen. Despite orthologous pairings of various Schlafens, these are all different proteins. Therefore, we will briefly summarize what is known about Schlafen biology in mice, then discuss Schlafen biology in humans, and, finally, mention viral biology.

Studies of Schlafen biology in mice have explored the roles of murine Schlafens in immunological function and immune cell differentiation [1,4], viral infections [30,31], bone development [32,33], and gut epithelial biology [29,34]. Slfn1, Slfn2, and Slfn3 are upregulated during the transition of immature $\mathrm{T}$ cells from $\mathrm{CD} 4^{+}$or $\mathrm{CD} 8^{+}$double-positive (DP) to single-positive (SP) [1]. Conversely, Slfn1 and Slfn2 (but not Slfn3) are downregulated in T cells upon activation and affect the growth and maturation of the T cell [1]. Both Slfn1 and Slfn2 are upregulated upon treatment with interferon-alpha (IFN- $\alpha$ ) in melanocytes [35], lipopolysaccharide (LPS) in microglia [36], and bleomycin treatment of alveolar MLE-12 cells [5], and in splenocytes after Listeria monocytogenes infection [4]. Slfn1 induces cell cycle arrest by inhibiting the induction of cyclin-D1 [8]. In addition to its effect on T cells, Slfn1 also inhibits endothelial progenitor cell proliferation and tube formation [8].

Slfn2 alters the growth and differentiation of mouse hematopoietic cells [37] and is critical for T cell quiescence [1]. Indeed, Elektra mice that have loss-of-function Slfn2 point mutation are immunodeficient with decreased numbers of $\mathrm{CD} 4^{+}$and $\mathrm{CD} 8^{+} \mathrm{T}$ cells and increased apoptotic $\mathrm{T}$ cells [38]. In addition, Elektra mice display increased de novo synthesis of cholesterol due to increased HMG-CoA reductase activity in T cells, causing lipid accumulation inside $\mathrm{T}$ cells that induces chronic endoplasmic reticulum stress [39,40]. Slfn2 upregulates in macrophages upon Toll-like receptor stimulation of Activator protein1 (AP-1) and nuclear factor kappa-light-chain-enhancer of activated B cells (NFKB) [41]. Moreover, Slfn2 is a key positive regulator of osteoclastogenesis in mice [32,33].

Slfn3 is expressed preferentially in $\mathrm{CD} 4^{+} \mathrm{CD} 25^{+}$Treg cells and downregulates during $\mathrm{T}$ cell activation by TGF- $\beta$ [42]. Outside the immune system, Slfn3 also regulates enterocytic differentiation [28,43,44] and colonic mucosal growth during aging [45]. Slfn3 knockout mice show gender-specific differences in weight gain, intestinal epithelial differentiation, and impaired enterocyte differentiation after bowel resection [46]. Although Slfn3 knockout mice have been reported to have no immune phenotype [38], intestinal epithelium from Slfn3 knockout mice exhibits downregulation of the transcriptome related to immune system pathways of intestinal immune network for IgA production, leukocyte transendothelial migration, and B cell receptor signaling [46].

Slfn4 expression decreases in T cells during growth and development and increases upon stimulation of the mature T cell [1]. In contrast, Slfn4 is downregulated during macrophage differentiation but upregulated during macrophage activation [47]. Mouse Slfn4 upregulates upon treatment with IFN- $\alpha$ in melanocytes [35], LPS in microglia [36], and bleomycin in alveolar MLE-12 cells [5], and also inhibits myelopoiesis upon Helicobacter infection through Gli-dependent pathway [48,49].

Slfn5, Slfn8, Slfn9, and Slfn10 are all upregulated in melanoma cells upon treatment with IFN- $\alpha$ [35] and in splenocytes after infection with Listeria monocytogenes [4]. Slfn8 regulates the development and the proliferation of peripheral T cells [4]. Transgenic mice expressing Slfn8 within the T cell lineages have an overall decrease in thymocyte number and reduced thymus size [4]. Conversely, Slfn 8 knockout mice are resistant to autoimmune encephalomyelitis [50].

In contrast to mice, humans express only intermediate and long Schlafens. SLFN5 is highly expressed in T cells and is downregulated upon T cell activation [51]. Also, SLFN5 is upregulated in astrocytes upon treatment with IFN- $\alpha$ [52], and in monocyte-derived dendritic cells after either IFN- $\alpha$ or LPS stimulation [51]. Moreover, SLFN5 acts as a 
transcriptional co-repressor of Signal Transducer And Activator Of Transcription 1 (STAT1) through direct interaction with STAT1 [52], and it has been identified as part of the Notch Receptor 1 (NOTCH1) nuclear interactome [53].

SLFN11 is expressed in monocytes and monocyte-derived dendritic cells [51] and is upregulated in monocyte-derived dendritic cells upon exposure to IFN- $\alpha$, LPS, or rhinovirus [51]. Similar to SLFN5, SLFN11 has been identified as part of the NOTCH1 nuclear interactome [53]. SLFN11 expression in $\mathrm{CD}^{+}$cells upregulates during HIV infection in elite controllers (individuals who maintain low HIV viral load without treatment) [12], and after antiretroviral therapy of HIV patients [13], suggesting the possibility that SLFN11 may be an important factor in the suppression of HIV replication. Indeed, SLFN11 inhibits HIV replication in a codon usage-dependent manner [30]. Interestingly, equine Slfn11 inhibits equine infectious anemia virus production by a similar mechanism [54]. Moreover, SLFN11 is differentially regulated during B cell maturation, and it is epigenetically suppressed in normal germinal center B cells [55].

SLFN12 is basally expressed by monocytes, monocytes-derived dendritic cells, and $\mathrm{T}$ cells. Its expression decreases in monocytes in response to various differentiation stimuli [51], while it is upregulated in monocytes-derived dendritic cells by exposure to IFN- $\alpha$, LPS, or rhinovirus [51]. SLFN12 is upregulated in T cells in the presence of ct-CD45 to maintain T cell quiescence [56]. SLFN12 regulates the differentiation of enterocytes by interacting with Serpin B12 and the deubiquitylases Ubiquitin Specific Peptidase 14 (USP14) and Ubiquitin C-Terminal Hydrolase L5 (UCHL5) to thereby affect the degradation of various transcription factors [29].

SLFN13 is expressed in monocytes, monocyte-derived dendritic cells, and T cells, is upregulated during the differentiation of monocyte into monocyte-derived dendritic cells [51], and further upregulated in monocyte-derived dendritic cells after exposure to IFN- $\alpha$, LPS, and rhinovirus [51]. Whether higher SLFN13 expression is simply a consequence of the differentiation or actually regulates it awaits exploration.

SLFN14 expression is upregulated upon influenza virus infection in human lung adenocarcinoma cells (A549), and it inhibits viral nucleoprotein expression and translocation to the nucleus [57]. Similarly, SLFN14 inhibits the replication of varicella zoster virus (VZV) in primary human dermal fibroblasts by reducing the expression of two major VZV proteins (glycoprotein E and immediate-early protein 62) that are needed for viral replication. SLFN14 co-localizes with ribosomes to mediate rRNA endonucleolytic degradation [58] and cleave rRNA and ribosome-associated mRNA [59]. SLFN14 mutations (K218E, K219N, V220D, R223W) cause thrombocytopenia in patients [60].

In addition to mice and humans, in 2007, Gubser et al. [61] identified viral slfn (v-slfn) in camelpox virus and other orthopoxviruses. Viral slfn shares similarity with mouse short Schlafens and is one of the host-range genes responsible for host tropism in camelpox virus infection [61]. Interestingly, v-slfn recruits the lymphocytes to the lung in mice. However, these lymphocytes are less active, suggesting that viruses may utilize v-slfn to dampen the host immune response [61].

\section{Schlafens in Cancer}

Although Schlafens were initially identified as proteins that influence immune cell maturation, differentiation, and responses to viral infections, recent studies have illuminated diverse potential roles for Schlafen proteins in cancer biology and malignant cell sensitivity to chemotherapy (Figure 2). The role of Schlafens in cancer has been chiefly investigated experimentally in mice and human cells and epidemiologically in humans. This review will address the effect of Schlafens in cancer in three sections. First, we will describe the role of Schlafens in the biology of different malignancies and their impact on survival, which has been chiefly investigated in humans. We will summarize the role of Schlafens in gastric cancer, malignant melanoma, lung cancer, breast cancer, gastric cancer, liver cancer, renal cancer, colorectal carcinoma, prostate cancer, central nervous system tumors, and hematological malignancies (Table 1). Second, we will summarize the role of 
Schlafens in the interferon immune response in cancer. Finally, we will summarize the role of Schlafens in cancer chemosensitivity to cytotoxic drugs.

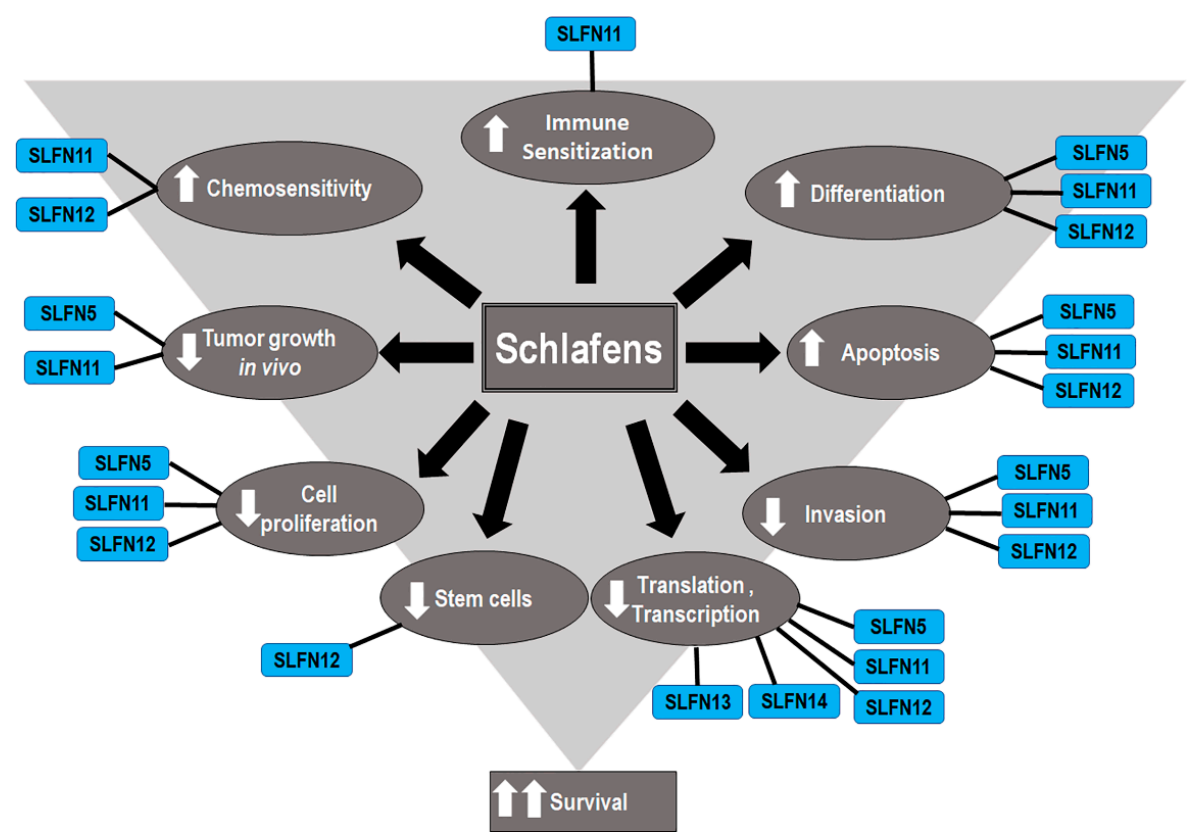

Figure 2. Diagram illustrates the identified effects of different Schlafens on cancer cell biology. The reduced cell proliferation, differentiation, invasion, and stem cells, in addition to the increased differentiation, immune sensitization, and chemosensitivity, all contribute to improved survival.

Table 1. Summary of the roles of human Schlafens in different cancer types. Each Schlafen expression level and the correlation with survival were identified. The non-cited data are derived from our analysis of publicly available tools (https:/ / www.proteinatlas.org, accessed on 10 July 2021) and (https: / / kmplot.com/analysis/, accessed on 10 July 2021).

\begin{tabular}{cccc}
\hline \multirow{2}{*}{ Cancer } & Schlafen & Expression Level & Survival Correlation \\
\hline \multirow{3}{*}{ Malignant Melanoma } & SLFN5 & Downregulated [62]. & Positive [62]. \\
\cline { 2 - 4 } & SLFN11 & No significant change. & Negative. \\
\cline { 2 - 4 } & SLFN12 & No significant change. & Negative. \\
\cline { 2 - 4 } Renal Carcinoma & SLFN14 & No significant change. & Positive. \\
\cline { 2 - 4 } & SLFN5 & Downregulated. & Positive [63]. \\
\cline { 2 - 4 } & SLFN11 & Downregulated [64]. & Positive [64]. \\
\cline { 2 - 4 } & SLFN12 & Downregulated. & Negative. \\
\hline \multirow{3}{*}{ Gastric Carcinoma } & SLFN14 & Downregulated. & Negative [16]. \\
\cline { 2 - 4 } & SLFN11 & Downregulated [65]. & Positive [65]. \\
\cline { 2 - 4 } & SLFN12 & Upregulated. & Not prognostic. \\
\cline { 2 - 4 } & SLFN14 & Downregulated. & Not prognostic. \\
\hline \multirow{3}{*}{ Colorectal Carcinomalated [16]. } & Negative. \\
\cline { 2 - 4 } & SLFN5 & No significant change. & Positive [22]. \\
\cline { 2 - 4 } & SLFN11 & Downregulated [22,64]. & Positive. \\
\cline { 2 - 4 } & SLFN12 & Downregulated. & Not prognostic. \\
\cline { 2 - 4 } & SLFN14 & Downregulated. & \\
\hline
\end{tabular}


Table 1. Cont.

\begin{tabular}{|c|c|c|c|}
\hline Cancer & Schlafen & Expression Level & Survival Correlation \\
\hline \multirow{4}{*}{ Lung Carcinoma } & SLFN5 & Downregulated $[64,66]$. & Positive [66]. \\
\hline & SLFN11 & Downregulated [22]. & Positive [67]. \\
\hline & SLFN12 & Downregulated [15]. & Positive [15]. \\
\hline & SLFN14 & Downregulated. & $\begin{array}{l}\text { Positive in lung } \\
\text { adenocarcinoma. }\end{array}$ \\
\hline \multirow{4}{*}{ Prostate Carcinoma } & SLFN5 & Upregulated [68]. & Negative [68]. \\
\hline & SLFN11 & $\begin{array}{l}\text { Upregulated in metastatic } \\
\text { prostate cancer [69]. }\end{array}$ & $\begin{array}{c}\text { No correlation to O.S., but } \\
\text { positive correlation to rPFS } \\
\text { [69]. }\end{array}$ \\
\hline & SLFN12 & Downregulated. & Not prognostic. \\
\hline & SLFN14 & Downregulated. & Not prognostic. \\
\hline \multirow{4}{*}{ Liver Cancer } & SLFN5 & Downregulated [70]. & Positive [70]. \\
\hline & SLFN11 & Downregulated [71]. & Positive [71]. \\
\hline & SLFN12 & Not Significant. & Negative. \\
\hline & SLFN14 & Downregulated. & Not prognostic. \\
\hline \multirow{4}{*}{ Esophageal Cancer } & SLFN5 & Upregulated. & No data available. \\
\hline & SLFN11 & $\begin{array}{c}\text { Downregulated with age } \\
\text { [72]. }\end{array}$ & Positive [72]. \\
\hline & SLFN12 & Upregulated & No data available. \\
\hline & SLFN14 & No significant change. & No data available. \\
\hline \multirow{4}{*}{ Breast Cancer } & SLFN5 & Downregulated $[73,74]$. & Positive $[73,74]$. \\
\hline & SLFN11 & Downregulated. & $\begin{array}{l}\text { Positive/negative after } \\
\text { hormone therapy [17]. }\end{array}$ \\
\hline & SLFN12 & Downregulated [14]. & $\begin{array}{l}\text { Positive in triple negative } \\
\text { breast cancer [14]. }\end{array}$ \\
\hline & SLFN14 & Downregulated. & Positive. \\
\hline \multirow{4}{*}{ CNS Tumors } & SLFN5 & Upregulated [52]. & Negative [52]. \\
\hline & SLFN11 & Upregulated [52]. & Negative [52]. \\
\hline & SLFN12 & Upregulated [52]. & Negative [52]. \\
\hline & SLFN13 & Upregulated [52]. & Negative [52]. \\
\hline \multirow{4}{*}{ Leukemia } & SLFN5 & No significant change. & No data available. \\
\hline & SLFN11 & Upregulated. & No data available. \\
\hline & SLFN12 & Upregulated. & No data available. \\
\hline & SLFN14 & Upregulated. & No data available. \\
\hline
\end{tabular}

\section{Expression of Schlafens in Cancer}

Our analysis of the TCGA pan-cancer database [75] shows cancer type-specific downregulation or upregulation of Schlafens (Figure 3). Human SLFN5, SLFN11, SLFN12, SLFN13, and SLFN14 are all downregulated in breast cancer, lung squamous carcinoma, prostate cancer, and rectal carcinoma. In contrast, these proteins are all upregulated in pancreatic and renal cell carcinoma (Figure 3). Other cancers exhibit a differential upregulation or downregulation of this family of proteins in a Schlafen-specific fashion (Figure 3). 


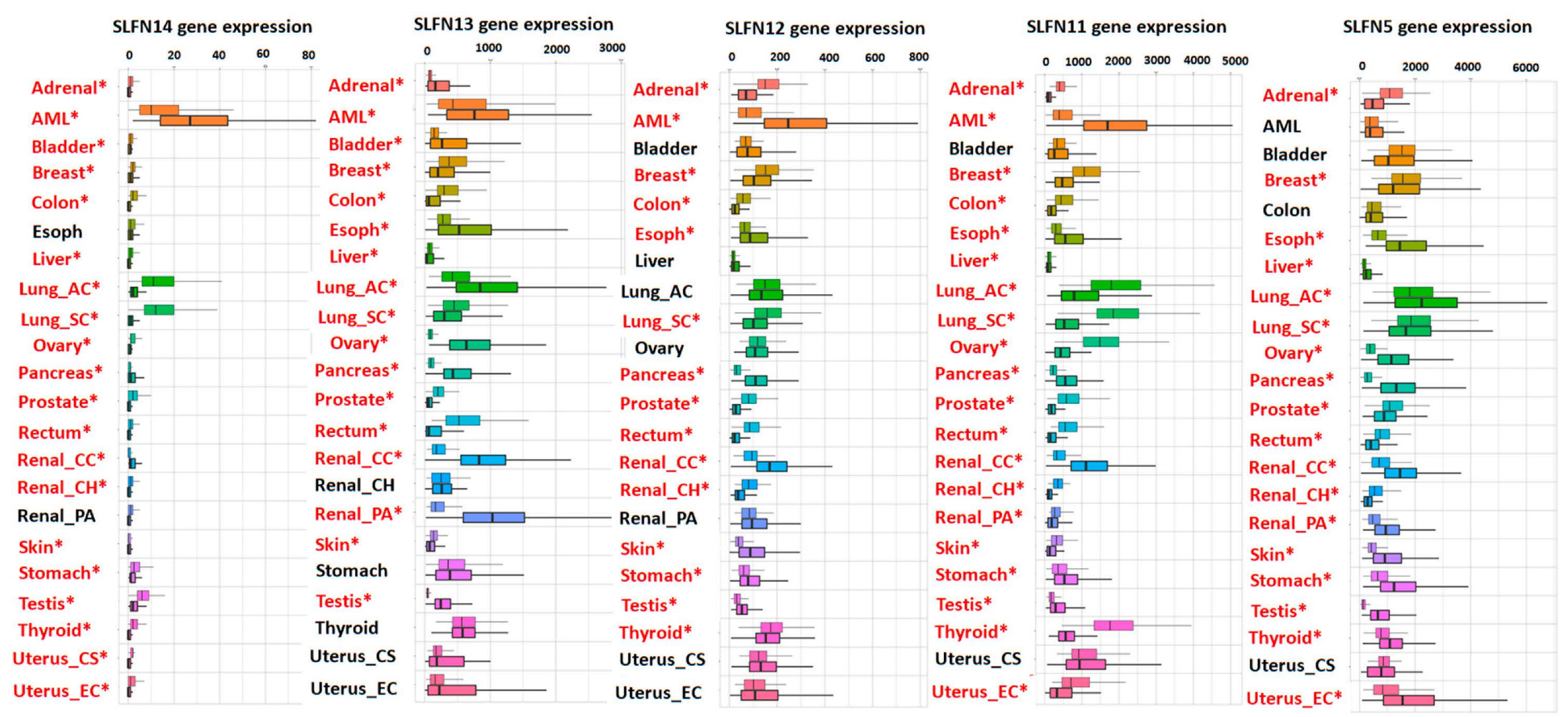

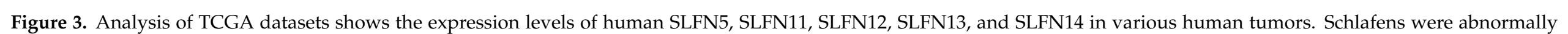

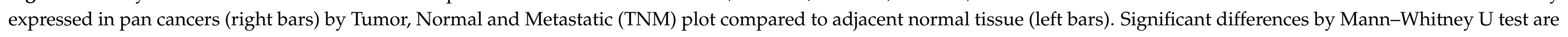

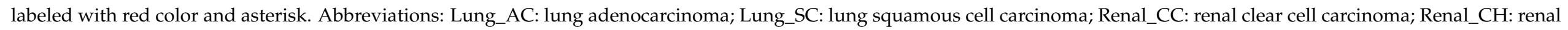
chromophobe cell carcinoma; Renal_PA: renal papillary cell carcinoma; Uterus_CS: uterine carcinosarcoma; Uterus_EC: uterine corpus endometrial carcinoma [75]. 


\section{Functions of Human Schlafens in Cancer}

Human Schlafens act through different mechanisms to induce their effects in cancer cells. This section will briefly outline what is known about the mechanism of action of each.

SLFN5 has been reported to act through several different mechanisms. SLFN5 negatively regulates the expression of the matrix metalloproteinase (MMP) genes MMP-1 and MMP-13 [63]. SLFN5 modulates epithelial to mesenchymal transition by regulating the $\beta$-catenin signaling pathway [76,77]. SLFN5 also binds and represses STAT1 transcriptional activity, and subsequently inhibits interferon-stimulated gene response to STAT1 [52]. SLFN5 also inhibits AKT Serine/Threonine Kinase (AKT) and Glycogen Synthase Kinase 3 Beta (GSK-3 $\beta$ ) phosphorylation [77] and upregulates Phosphatase And Tensin Homolog (PTEN) and AKT pathway by inhibiting the transcription of Zinc Finger E-Box Binding Homeobox 1 (ZEB1). Moreover, SLFN5 decreases cellular purine metabolites [73,74]. Finally, SLFN5 interacts with Activating Transcription Factor 4 (ATF4) and regulates the expression of Linker For Activation Of T Cells 1 (LAT1) (essential amino acids transporter), which in turn modulates the Mechanistic Target Of Rapamycin Kinase 1 (mTORC1) signaling pathway [68].

SLFN11 has been reported to increase chemosensitivity by five different mechanisms. First, SLFN11 is recruited to sites of DNA damage and interacts there with the Replication Protein A1 (RPA1) to inhibit checkpoint maintenance and homologous recombination repair [78]. Second, SLFN11 inhibits the translation of ataxia-telangiectasia mutated (ATM) and Rad3-related protein (ATR) (which are central components of the DNA damage response) by codon-specific translational inhibition [79]. Third, SLFN11 interacts with DDB1-CUL4CDT2 ubiquitin ligase to degrade Chromatin Licensing And DNA Replication Factor 1 (CDT1) and subsequently reactivates replication in response to chemotherapy leading to the collapse of replication forks and cell death [80]. Fourth, SLFN11 induces genome-wide chromatin accessibility at promoter regions during replication stress induced by DNA damaging agents [81]. Finally, SLFN11 is recruited to stressed replication forks, binds nascent DNA, and interacts with the replication helicase subunit (MCM3) without inhibiting initiation or loading of replication factor Cell Division Cycle 45 (CDC45) or the proliferating cell nuclear antigen (PCNA). This then allows SLFN11 to subsequently block replication in response to replication stress independently from ATR within 4 hours of induction of DNA damage [82].

SLFN12 binds Serpin B12 and subsequently modulates the deubiquitylases USP14 and UCHL5 to inhibit the proteasomal degradation of differentiation transcription factors such as cdx2 [29]. SLFN12 inhibits the translation of the oncogenes ZEB1 [14] and C-Myc [15]. SLFN12 is stabilized by interaction with Phosphodiesterase 3A (PDE3A) and is recruited and binds the ribosomes to exclude signal recognition peptides and subsequently inhibits translation [83]. In addition to these effects, SLFN12 has recently been identified as an RNAse that digests ribosomal RNA [84].

SLFN13, in contrast to other long Schlafens, is localized to the cytoplasm and acts as tRNA/rRNA-endoribonuclease that digests both tRNAs and rRNAs with a preference for tRNA, which inhibits protein synthesis [27]. In contrast, the long SLFN14 is a ribosomeassociated nuclear protein that binds to the ribosomal subunits and cleaves RNA, in particular rRNA and ribosome-associated mRNA, to control mRNA turnover and protein translation [59].

\section{Schlafens in Gastric Carcinoma}

Slfn4 has been suggested as a putative biomarker for intestinal metaplasia (gastric cancer precursor) in mice $[49,85]$. When mice are infected with Helicobacter felis, SLFN4 ${ }^{+}$ cells migrate to the stomach and express markers of the myeloid-derived suppressor cells that are responsible for the pro-inflammatory response leading to pre-neoplastic changes in Helicobacter-infected stomach [48]. Comparably, gastric tissues of H. pylori-infected patients show that SLFN12L (a human ortholog of Slfn4) co-localizes to cells that express Myeloid-derived suppressor cell (MDSC) markers $[49,85]$. Consequently, Slfn 4 marks the 
myeloid-derived suppressor cell recruitment that predicts a shift of gastric mucosa to a metaplastic phenotype [49]. Slfn4 (mRNA and protein) peaks at 4 and 6 months after $H$. felis infection in the stomachs of infected mice and coincides with the onset of spasmolytic polypeptide-expressing metaplasia (SPEM) [48]. This mouse study motivated further study of human orthologs that yielded comparable results. SLFN12L immunoreactivity is not detectable in non-malignant normal human gastric mucosa without $H$. pylori infection, with no observable labeling in mucosal immune cells. However, SLFN12L ${ }^{+}$immune cells are observed in H. pylori-infected gastric mucosa with intestinal metaplasia $[49,85]$. These SLFN12L $\mathrm{L}^{+}$immune cells are also $\mathrm{CD}^{+} 5^{+}$(a granulocytic-MDSC marker) and are localized near metaplastic glands. Similar to the mouse study, human SLFN12L expression increases in $H$. pylori-infected individuals with intestinal metaplasia and marks a GranulocyticMDSC subpopulation $[49,85]$. Therefore, human SLFNs such as SLFN12L (orthologous to Slfn4) might serve as biomarkers for identifying pre-neoplastic transformation of the gastric mucosa in humans. These studies illustrate the potential utility of murine Schlafens in murine cancer models as a method to predict the functions of human Schlafens.

Although normal human gastric mucosa has been reported to express minimal or no SLFN5 protein $[49,85]$, SLFN5 expression is upregulated in patients with atrophic gastritis, both intestinal and diffuse subtypes of gastric carcinoma, and in intestinal metaplasia that has progressed to gastric cancer [16]. In parallel, human normal gastric mucosa without $H$. pylori infection demonstrates negative labeling for both SLFN12L and SLFN5-expressing immune cells, but SLFN12L/SLFN5 ${ }^{+}$cells are observed in $H$. pylori-infected gastric mucosa with intestinal metaplasia $[49,85]$. Therefore, SLFN5 and SLFN12L gastric stromal expression could serve as a potential predictor of intestinal metaplasia progression to gastric carcinoma. Combining SLFN5 or SLFN12L expression levels with the histological examination of intestinal metaplasia tissue samples could substantially increase the probability of identifying patients with intestinal metaplasia that are at higher risk of progression to gastric carcinoma. The potential role of SLFN12, which shares a very high degree of similarity with SLFN12L, awaits exploration in gastric cancer.

In contrast to the apparent adverse roles of SLFN5 and SLFN12L in gastric cancer, analysis of gastric carcinomas from 169 patients suggested that high SLFN11 expression correlates with better survival, which improves when patients are treated with platinumchemotherapy [65]. Furthermore, in vitro knockout and reactivation of SLFN11 in gastric carcinoma cell lines (MKN-1, MKN-7, MKN-45, and MKN-74) causes resistance and sensitivity to platinum-based chemotherapy, respectively [65]. Conversely, long-term oxaliplatin treatment in both gastric carcinoma cells and organoids reduces SLFN11 expression, causing oxaliplatin resistance that is reversed by reactivation of SLFN11 (with epigenetic modifying drugs). Such data suggests a role for SLFN11 downregulation in gastric cancer development and a possible clinical role for SLFN11 levels in drug selection for gastric carcinoma patients [65].

These results suggest opposing roles for SLFN5, SLFN12L, and SLFN11 in gastric cancer is not necessarily surprising since these are different proteins although of the same family. They also illustrate that Schlafens have a cell-type and cancer-type specific effect.

\section{Schlafens in Malignant Melanoma}

Knockdown of Slfn2 or Slfn3, but not Slfn5, increases proliferation and anchorageindependent growth in murine melanoma cells [35]. Human primary melanocytes detectably express SLFN5, SLFN11, SLFN12, SLFN13, and SLFN14, with SLFN5 being the highest expressed Schlafen [62]. Although SLFN11, SLFN12, SLFN13, and SLFN14 are expressed comparably in primary melanocytes and malignant melanoma cells, the high expression of SLFN5 in primary melanocytes is suppressed at both mRNA and protein levels in malignant melanoma cells. [62] Further SLFN5 knockdown promotes anchorageindependent growth and invasion in human malignant melanoma cells [62]. This suggests a specific role of SLFN5 in the pathogenesis of melanomas and the importance of SLFN5 
downregulation in promoting melanoma tumorigenesis. More work is needed to elucidate or exclude any potential role of other Schlafens in malignant melanoma.

\section{Schlafens in Renal Carcinoma}

Higher SLFN5 expression correlates with better overall survival of patients with renal cell carcinoma [63]. In vitro overexpression of SLFN5 reduces the motility and invasiveness of malignant human renal cell carcinoma (RCC) cells by negatively regulating the expression of MMP-1 and MMP-13 [63]. Although SLFN5 expression has been studied in normal and cancerous renal cells, whether SLFN5 expression is downregulated or upregulated in renal carcinoma compared to adjacent non-tumor tissue has not been previously reported. Our analysis of the TCGA dataset (Figure 3) suggested that SLFN5 expression is significantly downregulated in RCC and renal papillary cell carcinoma, but it is upregulated in renal chromophobe cell carcinoma (Figure 3). Unlike SLFN5, SLFN11 expression is reduced in renal tumors compared to the adjacent non-tumorous tissue in both papillary renal cell carcinoma and chromophobe renal cell carcinoma [64], raising the possibility that SLFN11 downregulation may contribute to tumorigenesis in both papillary and chromophobe RCC. SLFN11 expression is also strongly correlated with the expression of $\mathrm{CD} 47$, a cell surface marker that sensitizes cancer cells to chemotherapy and radiotherapy, in RCC [86], while exogenous SLFN11 overexpression sensitizes CD47 negative cancer cells to radiotherapy [86].

These studies suggest a positive effect on survival for expression of both SLFN5 and SLFN11 in human RCC. However, the statistical effects of SLFN5 expression on survival in the subtypes of renal cancers (papillary renal cancer and chromophobe renal cancer) await exploration. Either SLFN5 or SLFN11 downregulation might be a part of the tumorigenesis in RCC, which awaits further study.

\section{Schlafens in Colorectal Carcinoma}

Colorectal cancer (CRC) is one of the most common cancers. Our clinical approach to this disease has included more aggressive surveillance, less invasive surgical techniques, and interference with Vascular Endothelial Growth Factor (VEGF) and Endothelial Growth Factor (EGF) receptors in metastatic disease [87,88]. A better understanding of the molecular biology of these tumors is certainly desirable. Colon cancer tissues show consistently negative immunohistochemical labeling for SLFN11 [64]. SLFN11 is methylated in more than half of the examined samples of human CRC, with no similar methylation seen in non-cancerous colorectal mucosa [22]. Hypermethylation of the SLFN11 CpG promoter inactivates SLFN11 gene expression in cancer cells [21], which might contribute to the reported negative SLFN11 labeling in colon cancer. Moreover, methylation of SLFN11 (which correlates with SLFN11 expression) significantly correlates with age, poor 5-year overall survival, and poor 5-year relapse-free survival in colon cancer [22]. Therefore, SLFN11 methylation (which inversely correlates with SLFN11 expression [21]) could serve as an independent prognostic factor for overall and relapse-free survival in colon cancer [22]. In vitro, exogenous expression of SLFN11 in CRC cell lines that express low levels of endogenous SLFN11 suppresses the aggressive behavior of such cells by reducing cell proliferation and colony formation and reducing the expression of cyclin D1 and cyclin E1. Conversely, expression of cyclin D1 and cyclin E1 increases after knockdown of SLFN11 in DKO colon cancer cells that express high endogenous SLFN11 [22]. Interestingly, SLFN11 sensitizes RKO, DLD1, and SW620 colorectal cancer cells to cisplatin and reduces in vivo tumor growth in mice [22], suggesting a favorable role for SLFN11 in CRC. As for gastric cancer, SLFN11 expression could be a prognostic marker for gastric and colon cancers. Although SLFN11 is a long SLFN that targets to the nucleus, SLFN12 is an intermediate SLFN that acts in the cytosol (Figure 1). Overexpressing SLFN12 in human colon adenocarcinoma cells induces the differentiation of such cells by modulating the activity of the deubiquitylases USP14 and UCHL5 [29]. 
Interestingly, the effect of Schlafens on colon cancer extends beyond the human Schlafens, as exogenous expression of mouse Slfn3 in human CRC cell lines that lack Slfn3 induces G0/G1 arrest by downregulating Cyclin D1 expression and reducing phosphorylation of retinoblastoma (pRB) protein [45]. Slfn3 expression in human colon cancer cells induces differentiation, inhibits TGF- $\alpha$ expression, and reduces the cancer stem cell population within a heterogeneous cell population, and inhibits colonosphere formation $[11,28,43]$. In addition to influencing native differentiation, Slfn3 overexpression modulates the response to chemotherapy, downregulating the expression of ATP Binding Cassette Subfamily G Member 2 (ABCG2), which transports chemotherapeutic drugs, and stimulating apoptosis in response to additional folic acid, fluorouracil, and oxaliplatin (FOLFOX) treatment in FOLFOX-resistant HCT-116 and HT-29 cells [11]. Although Slfn3 is not expressed in humans, such findings might predict the role of human orthologs of Slfn3 (SLFN12) in colon cancers and further support the need to explore the potential role of SLFN12 in colon cancer.

\section{Schlafens in Lung Cancer}

SLFN12 correlates with survival in patients with lung adenocarcinoma but not in patients with lung squamous cell carcinoma [15]. In vitro, overexpressing SLFN12 in lung adenocarcinoma cells reduces proliferation by inhibiting c-myc translation, with no similar effect on c-myc or cell proliferation in lung adenocarcinoma cells [15], demonstrating a specific SLFN12 effect in one distinct subtype of lung cancer (lung adenocarcinoma).

SLFN5 protein expression positively correlates with the overall survival in non-small cell lung cancer (NSCLC) [66]. Although both SLFN5 and SLFN11 are downregulated in NSCLC vs. adjacent non-cancerous tissue specimens $[64,66]$, higher SLFN5 expression is detected in early-stage NSCLC tissues [66]. SLFN5 expression is highly correlated with the clinicopathological characteristics of NSCLC (TNM classification) [66], suggesting that SLFN5 may contribute to tumorigenesis and progression of lung cancer. However, studies of SLFN5 have not yet distinguished among the different histological subtypes of NSCLC, which may be worthwhile given the differential relevance of SLFN12 in NSCLC subtypes [15].

In vitro, SLFN5 knockdown in A549 adenocarcinoma human alveolar basal epithelial cells upregulates metalloproteinases, specifically matrix metalloproteinase MMP9. This facilitates cell invasion and, indeed, increases A549 cell two-dimensional migration [66], although true invasion was not addressed in that study. This would be important to address since true invasion is more complex than cell motility and requires a balance between matrix metalloproteinase activities and TIMP levels that is not necessarily predictable by the expression of a single matrix metalloproteinase. Guo et al. [76] similarly reported that SLFN5 overexpression induced epithelial to mesenchymal transition in A549 cells, promoting nuclear translocation of $\beta$-catenin and expression of Snail and vimentin, while downregulating E-cadherin and increasing both two-dimensional migration and invasion [76]. Conversely, A549 cells, in which SLFN5 has been reduced, displayed epithelial morphology with upregulated E-cadherin and downregulated vimentin and decreased cell migration and invasion [64]. In contradiction to the findings of Guo et al. [76], Wan et al. [77] reported that lung adenocarcinoma A549 cells have high SLFN5 expression. Furthermore, reducing SLFN5 in these cells activated the $\beta$-catenin signaling pathway, enhancing Metallothionein 1 (MT1)-MMP expression and increasing migration and invasion of A549 lung adenocarcinoma cells in vitro and even in vivo, when SLFN5 knockout A549 cells were injected in chorioallantoic membrane of the chick embryo [77]. Indeed, Wan and colleagues [77] reported similar findings in MCF7 (breast) and HCT-116 (colon) cancer cell lines that are also less invasive [77]. The discrepancy in the reported effect of SLFN5 knockdown in A549 lung adenocarcinoma cells between these studies could reflect differences in cell passage or type between the two laboratories with phenotypic drift. However, it is noteworthy that Guo et al. [76] performed stable SLFN5 transfection/knockdown of A549 cells with a lentiviral vector while Wan et al. [77] used transient transfection/knockdown. 
The adaptation of A549 cells to the continuous stable loss of SLFN5 or off-target effects of the transient knockdown could affect other Schlafens. Manipulating levels of one Schlafen protein may affect others by feedback loops that await elucidation [89]. Therefore, it would be interesting and potentially explanatory to examine the expression of other endogenous Schlafen proteins in the experiments described by Guo et al. [76] and Wan et al. [77].

SLFN11 expression is prognostically significant and correlates with improved patient outcomes after adjuvant chemotherapy in lung squamous cell carcinoma [67]. Furthermore, in lung squamous cell carcinoma, but not lung adenocarcinoma, SLFN11 expression correlates with the expression of CD47 (a cell surface molecule that sensitizes cancer cells to radiotherapy and chemotherapy) [86]. This indicates a role of SLFN11 in the radiosensitivity of lung squamous cell carcinoma. Although not examined in lung cancer cells, increasing SLFN11 expression in CD47 knockout Jurkat cells restored their radiosensitivity [86].

\section{Schlafens in Prostate Cancer}

The role of each Schlafen has not been studied extensively in all subtypes of prostate cancer. Most studies have examined the role of Schlafens in castration-resistant prostate cancer. The expression of some Schlafens seems favorable, while others correlate with more aggressive prostate cancer behavior.

SLFN5 is identified as an androgen receptor-regulated protein in castration-resistant prostate cancer (CRPC). CRPC tumors exhibit high SLFN5 expression, which correlates with poor patient outcome [68]. SLFN5 is also among thirty upregulated genes in docetaxelresistant C4-2B and LNCaP prostate cancer cells [90]. In vitro, SLFN5 depletion strongly reduces tumor growth in CRPC by decreasing intracellular levels of essential amino acids and impairing mTORC1 signaling [68]. Therefore, as in gastric cancer, SLFN5 expression is an unfavorable prognostic predictor for CRPC. The potential role of SLFN5 in other subtypes of prostate cancer awaits exploration.

Circulating tumor cells (CTCs) from metastatic CRPC patients show SLFN11 gene methylation, suggesting the need for SLFN11 silencing in prostatic cancer cells to gain metastatic ability [91]. SLFN11 re-upregulates in the circulating tumor cells upon treatment with platinum-based drugs, implicating SLFN11 upregulation in the CRPC response to platinum therapy [69]. In contrast, SLFN11 is not overexpressed in neuroendocrine prostate cancer patients treated with platinum, and it has remained lower than CRPC with adenocarcinoma histology [69], indicating that SLFN11 upregulation in response to platinum-based chemotherapy is specific to prostatic adenocarcinoma. Unlike SLFN5, no significant correlation is observed between SLFN11 expression and overall survival, but a longer radiologic progression-free survival (rPFS) is seen in CRPC patients with adenocarcinoma histology with SLFN11 overexpression vs. low SLFN11 expression in patients that are treated with platinum-based chemotherapy, and no similar effect on rPFS is observed in neuroendocrine prostate cancer [69]. Also, SLFN11-overexpressing prostate cancer patients show less serum prostatic specific antigen (PSA) than patients with low SLFN11 tumors [69]. SLFN11 expression increases the sensitivity of prostate cancer cells to platinum-based drugs in vitro, and knockout of SLFN11 in human prostate cancer organoids increases the resistance to Cisplatin and Olaparib (Poly (ADP-ribose) polymerase inhibitors, PARPi) in prostatic organoids [69].

Similar to what has been observed in lung cancer, CD47 positively correlates with SLFN11 expression in prostate carcinoma but not in normal prostate tissue [86]. Moreover, knockdown of CD47 in prostate cancer PC3 cells reduces both SLFN11 mRNA and protein levels, indicating SLFN11 is a target of CD47 in prostate cancer cells [86]. Although SLFN11 knockdown does not protect CD47-null PC3 cells from the effect of ionizing radiation as in other cancer cells, the low SLFN11 in CD47-null PC3 cells reduces the sensitivity of these cells to DNA damaging agents such as etoposide [86]. In addition, SLFN11 protein levels increase 24 hours after treating wild type PC 3 cells with sublethal doses of rocilinostat, entinostat (HDACs), or etoposide. CD47-null PC3 cells lack SLFN11 expression induction by such drugs, indicating a CD47-dependent effect of HDAC inhibition on 
SLFN11 expression in PC3 cells [86]. Moreover, CD47 regulates SLFN11 expression in prostate cancer through promotor methylation [86].

Unlike the nuclear-localized SLFN5 and SLFN11 [25], the intermediate family SLFN12, which lacks nuclear import signal and localizes to the cytoplasm [10], also has a differentiation effect in prostate cancer cells [92]. Overexpressing SLFN12 in prostate cancer LNCaP and PC-3 cells induces the differentiation of these cells as indicated by the reduced PSA expression and increased dipeptidyl-peptidase- 4 and E-cadherin expression independently of the other known differentiation pathways [92]. Although this SLFN12 study did not conduct survival analysis in prostate cancer, better differentiation of cancer cells is known to have a better outcome; therefore, SLFN12 expression is predicted to correlate with better prostate cancer outcomes [92].

\section{Schlafens in Liver Cancer}

Only SLFN5 and SLFN11 have been investigated in liver cancer. SLFN11 mRNA and protein are downregulated in hepatocellular carcinoma (HCC) vs. non-tumor liver tissues [71]. Low SLFN11 expression correlates with shorter overall survival, higher recurrence rates, and more aggressive clinicopathologic characteristics in HCC patients [71]. SLFN11 expression is negatively correlated with high serum alpha-fetoprotein levels (a marker widely used to detect HCC), tumor size, microvascular invasion, and advanced stage [71]. L-02 normal liver cells have higher SLFN11 expression than HCC cell lines, and overexpressing SLFN11 in HCC cell lines (HCCLM3, Hep3B, SMMC-7721, and PLC/PRF/5) inhibits cell proliferation, migration/invasion, induces apoptosis, and reduces HCC growth and metastasis in vivo. All these effects are attenuated by SLFN11 knockdown [71].

SLFN5 is also downregulated in hepatocellular carcinoma. Lower SLFN5 expression correlates with poor survival and more aggressive clinicopathological features (TNM) of the disease [70]. As for SLFN11, normal liver cells (L-02) have higher SLFN5 expression (mRNA and protein) than HCC cell lines (SMMC-7721, BEL-7402, Huh 7, HepG2 cells) [91]. Mechanistically, SLFN11 physically binds RPS4X and attenuates both S6 and eIF4E phosphorylation, blocking mTOR signaling [71]. Overexpression of SLFN11 in an orthotopic mouse model reverses HCC progression and metastasis [71]. Hence, SLFN5 and SLFN11 may be used as prognostic biomarkers. Furthermore, SLFN11 may be a tumor suppressor that blocks mTOR signaling in HCC and therefore a potential therapeutic target in HCC patients.

\section{Schlafens in Esophageal Cancer}

High SLFN11 expression is correlated with a better prognosis in esophageal squamous cell carcinoma patients [72]. The prognostic value of high SLFN11 expression is most prominent in patients at clinical stages II and III who received definitive chemoradiation therapy (combination of nedaplatin, 5- fluorouracil, and irradiation) [72]. Although this has not been investigated in vitro in esophageal cancer cells, the SLFN11-positive leukemic cell lines K562 and CCRF-CEM are more sensitive to platinum derivatives, but not 5-fluorouracil compared to SLFN11-knockout cells. [72] Thus, it is possible that the observed SLFN11-dependent improvement in clinical outcome in esophageal squamous cell carcinoma may reflect the improved response of tumors expressing high SLFN11 to platinum but not 5-fluorouracil. Therefore, SLFN11 expression could be a prognostic marker for esophageal squamous cell carcinoma and a potential biomarker for therapy selection in esophageal squamous cell carcinoma [72]. No data is available regarding the role of Schlafens in esophageal adenocarcinoma, which still awaits exploration.

\section{Schlafens in Breast Cancer}

Two Schlafens have been reported to similarly correlate with breast cancer biology but by different mechanisms. Expression of both the long SLFN5, which targets to the nucleus, and the intermediate SLFN12, which targets to the cytosol, is correlated with survival, tumor growth, and metastasis in triple negative breast cancer $[14,73,74]$. SLFN5 
expression has also been reported to correlate inversely with metastasis in Luminal A breast cancer [73]. Although overexpression of either SLFN5 or SLFN12 in invasive breast cancer cell line (MDA-MB-231) induces mesenchymal-epithelial transition (MET) and increases E-cadherin, and reduces vimentin expression by modulating ZEB1, they do so through different mechanisms. SLFN5 inhibits the transcription of ZEB1 through direct promoter binding [73]. It subsequently upregulates the transcription of PTEN (a known cancer suppressor gene), induces molecular changes in the downstream AKT pathway, and proliferation/apoptosis in both $\mathrm{ER}^{+} / \mathrm{PR}^{+} \mathrm{MCF}-7$ and ER $/ \mathrm{PR}^{-} \mathrm{MDA}-\mathrm{MB}-231$ cells [74]. SLFN5 also decreases purine metabolites (inosine, xanthine, and hypoxanthine) in breast cancer cells [74]. In contrast, SLFN12 inhibits ZEB1 translation without transcriptional inhibition, induces $\mathrm{CD} 44^{+} / \mathrm{CD} 24^{-}$stem cell differentiation, and reduces the proliferation of triple negative breast cancer cells but not the $\mathrm{ER}^{+} / \mathrm{PR}^{+} \mathrm{MCF}$ cells [14]. Such differences in mechanistic action might be attributed to the different localization of SLFN5 and SLFN12, as SLFN5 localizes to the nucleus [25], while SLFN12 localizes to the cytoplasm [29] and lacks the nuclear localization signal that is present in SLFN5. Interestingly, deletion of the C-terminal of SLFN5 abolishes the SLFN5 effect on ZEB1, indicating that the activity of SLFN5 requires the C-terminal domain that harbors the nuclear import signal [73]. In contrast, point mutations that disrupt the central domain of SLFN12 (D233Q, Y236F) abolish SLFN12 differentiating effect in Caco-2 cells [29].

Such data encourage exploring the role of Schlafens in various subtypes of cancer rather than aggregating all types of cancer in a given organ or tissue together and suggests SLFN5 and SLFN12 as potential therapeutic targets for breast cancer.

In contrast to the reported positive effects of SLFN5 and SLFN12 in breast cancer, high SLFN11 expression correlates with more aggressive breast cancer tumors with signs of immune activation (basal-like phenotype, higher histological grade, younger age), while lower SLFN11 expression is noted in the luminal, less aggressive neoplasms characterized by low immune activation [17]. Moreover, SLFN11 positively correlates with markers of lymphocytic tumor infiltration such as CD3 and CD8 in breast cancer [17]. Interestingly, similar to SLFN5 and SLFN12, SLFN11 overexpression is independently associated with a better prognosis. However, patients with high SLFN11 and undergoing hormone therapy have a short-term worse prognosis in the first two years [17]. This could be because high SLFN11 breast cancers are mostly ER-negative, basal-like phenotype that are known for their poor response to hormonal therapy [17,93]. Another study examined the patient-derived xenografts (PDXs) response to DDA and has shown SLFN11 is significantly elevated in metastatic tumors compared to non-metastatic ones, and high SLFN11 metastatic PDXs showed better response to therapy with DNA damaging agents [94].

Unlike the observation with SLFN11, SLFN12 expression is correlated with endocrine therapy sensitivity in estrogen-positive breast cancer, as SLFN12 is one of the 60 differentially methylated region (DMR) genes in breast cancers with endocrine resistance. The CpG methylation of promotor region of SLFN12 gene is correlated with lower mRNA expression and subsequently endocrine therapy resistance [95].

\section{Schlafens in Central Nervous System Cancers}

Strikingly, all the examined human Schlafens may be poor prognostic indicators in neurological tumors. In glioblastoma multiforme (GBM), high levels of all human Schlafens (SLFN5, SLFN11, SLFN12, and SLFN13) are correlated with shorter overall survival of patients [52]. Specifically, the expression levels of SLFN5, SLFN11, and SLFN12 are positively correlated with glioma grade, highest in the more aggressive grade IV compared to grade I, II, or III tumors [52]. Knockdown of SLFN5 in GBM cells (LN18 and U87MG) reduces proliferation, anchorage-independent growth, invasiveness, and tumorigenesis in vivo when cells are injected in mice [52]. 


\section{Schlafens in Hematological Malignancies}

Although Schlafens were discovered initially in immune and hematological cells with varying expressions during different stages of differentiation and growth $[51,56]$, the role of Schlafens in leukemia development and progression has not been examined extensively.

Silencing Slfn2 prevents the growth of pre-leukemic T cells in T cell acute lymphoblastic leukemia (T-ALL), which is induced by the intracellular domain of NOTCH1 (ICN1) [96] and attenuates the development and the progression of T-ALL in mice [96]. Furthermore, the loss of function of Slfn2 in Elektra mice protects these mice from ICN1-induced TALL [96], while knockdown of Slfn2 in EL4 (a murine T cell lymphoma cell line) reduces its proliferation, attenuates $\mathrm{T}$ cell lymphoma development when injected in mice, and improves survival [96]. Part of these positive effects is due to p53 pathway activation [96].

A novel missense mutation (E261Q) of SLFN12 gene has been discovered in CD4 ${ }^{+} \mathrm{T}$ cells of patients with Sezary syndrome ( $T$ cell cutaneous lymphoma) [97]. Overexpressing SLFN12 in the continuously proliferating Jurkat cells ( $T$ cell leukemia cell line) reduces the overall cellular growth and viability [56].

SLFN11 modulates the sensitivity of HAP1 cells (derived from chronic myelogenous human leukemia) to T cell mediated cytotoxicity [98]. Interestingly, silencing SLFN11 expression reduces the sensitivity of HAP1 to both IFN- $\gamma$ and DNA damaging agents [98].

\section{Role of Schlafens in the Antitumor Effects of Interferons}

The interferons have long been known to have anti-tumor effects, particularly in hematological cancers $[99,100]$. Although interferons stimulate a wide array of genes responsible for the complex responses of cancer cells to interferons, the exact mechanistic pathway through which interferons act remains unclear.

Schlafens are interferon regulatory factor (IRF-1) dependent [4] interferon-stimulated genes [26]. Interferon (IFN $\alpha$ ) induces the expression of Slfn1, Slfn2, Slfn3, Slfn4, Slfn5, and Slfn8 in B16-F1 malignant murine melanoma cells and murine renal cell carcinoma cells (RCC) [35]. Knockdown of Slfn2 or Slfn3, but not Slfn5, increases cell proliferation and anchorage-independent growth and reduces the antiproliferative effect of interferon in murine melanoma cells [35]. However, reducing Slfn5 in mouse renal cell carcinoma cells increases cell proliferation and anchorage-independent growth, and reduces the antiproliferative effect of interferon [35].

Interestingly, IFN-I substantially upregulates SLFN5 in malignant melanoma cells [62], in normal renal proximal tubule epithelial cells (RPTEC), and human renal adenocarcinoma cells (786-O and ACHN RCC cells), with minimal or no induction of other human Schlafens [62]. This suggests a potential role of SLFN5 in the anti-tumor effects of IFN- $\alpha$ in humans. Unlike the observations in malignant melanoma and RCC, SLFN5 inhibits the anti-tumor effect of interferon in glioma multiforme cells by binding and co-repressing STAT1 stimulation. Knockdown of SLFN5 enhances cellular sensitivity to IFN-induced antiproliferative responses in glioma stem-like cancer cells, making SLFN5 a negative regulator of the IFN-response in glioma cancer cells [52]. IFN also upregulates the expression of SLFN11, SLFN12, SLFN13, and SLFN14 in various benign and malignant neural cells, but whether these upregulated SLFNs contribute to the activity of the interferon has not yet been studied [52].

An extensive study is required to dissect the role of each Schlafen in response to interferons therapy in each cancer subtype, and to identify the magnitude of interferon anti-tumor response in high Schlafen expressing vs. low expressing tumors, which may predict the patients who could benefit from interferon therapy.

\section{Role of Human Schlafens in Cancer Chemosensitivity}

\subsection{Role of Schlafen 11 in Chemosensitivity}

In vitro observations have implicated SLFN11 as a potential marker of cancer cell chemosensitivity to agents as diverse as PARPi [69,101-106], platinum-based drugs $[21,65,69,94,107]$, topoisomerase inhibitors [18,108-112], and antibody-drug conju- 
gates [112] in a variety of tumor types including breast [67,94,101], lung [21,67,101,103,104,107], ovarian [21,67], prostate [69,101], colon [101,108], Ewing sarcoma [101,109], gastric carcinoma [65], and leukemias [108,111]. Mouse studies showed that high SLFN11 expression increases the synergistic effect of talazoparib-temozolomide in small cell lung carcinoma xenografts [101]. Moreover, in xenografts derived from triple negative breast cancer patients, SLFN11 has been identified in the top upregulated genes in irinotecan responders compared to the resistant xenografts [110]. High SLFN11 expression also predicts sensitivity to doxorubicin in these xenografts [110]. High SLFN11 expression in prostate cancer patient-derived xenografts also increases their sensitivity to LMP400 [111]. Indeed, in humans, epidemiologic data suggest that SLFN11 expression is higher in patients with ovarian, lung, or breast cancer who respond to chemotherapy [67] and in patients with gastric carcinoma who survive longer [65].

\subsection{Role of Schlafen 12 in Chemosensitivity}

Drug resourcing has identified SLFN12 as a target of 6-(4-(diethylamino)-3-nitrophenyl)5-methyl-4,5- dihydropyridazin-3(2H)-1 (DNMDP). DNMDP promotes phosphodiesterase 3A (PDE3A) physical interaction with SLFN12 and induces apoptosis in 766 cancer cell lines [113,114], and depleting SLFN12 decreases the DNMDP sensitivity [114]. DNMDPderived molecule (R)-30/BRD9500 induces PDE3A/SLFN12 interaction in cervical adenocarcinoma HeLa cells to promote apoptosis [115]. Also, this molecule has shown activity with oral dosing in melanoma xenografts [115]. High SLFN12 expressing cancer cells are more sensitive to PDE3 inhibitors (zardaverine and quazinone) than low SLFN12 expresser cells [116]. Additionally, the sensitivity to zardaverine and quazinone (PDE3 inhibitors) in primary cultures of patient-derived ovarian cancer correlates with both SLFN12 and PDE3A expression [116]. Interestingly, SLFN12 induces apoptosis in Hela cells (cervical adenocarcinoma) in response to 17-B-estradiol (E2) treatment [83]. Upon 17-ßB-estradiol binding to phosphodiesterase $3 \mathrm{~A}$ (PDE3A), PDE3A in turn recruits, binds, and stabilizes SLFN12. In turn, SLFN12 inhibits the translation of antiapoptotic proteins, and consequently activates the mitochondrial pathway of apoptosis [83]. Similar to 17-B-estradiol, nauclefine (an indole alkaloid natural product) also induces PDE3A-SLFN12-dependent apoptosis in HeLa cells [117].

SLFN12 mutations can reduce DNMDP sensitivity even in the presence of high PDE3A expression, as noted in CAL51 cells, which harbor heterozygous SLFN12 nonsense gene mutation at amino acid 196 [118]. Moreover, a SLFN12 (I105N) mutation prevents SLFN12PDE3A interaction and abolishes the cell death effect of nauclefine in Hela cells [117].

\section{Conclusions}

Although it has been more than twenty years since Schlafens were discovered, they remain intriguing proteins and are still enigmas. The exploration of the role of Schlafens in cancers is still in its early stages and evidence predicts a considerable role for Schlafens in tumorigenesis, as biomarkers and predictors for chemotherapy, and as possible targets for drugs.

The role of Schlafens is not universal, and each Schlafen has a distinct specific mechanism through which it affects cancer cell biology. Interestingly, this mechanism is not alike in all cancer types/subtypes. Instead, Schlafens demonstrate different effects in different subtypes of tumors of the same organ.

The complex signaling networks through which Schlafens are reported to act in cancer urges extensive future characterization and exploration of each Schlafen in the different cancer subtypes, which will eventually push us closer to better understand cancers in humans. 
Author Contributions: Conceptualization, S.A.-M., E.E.V.-D., and M.D.B.; writing-original draft preparation, S.A.-M.; writing-review and editing, E.E.V.-D. and M.D.B.; supervision and project administration, M.D.B. All authors have read and agreed to the published version of the manuscript.

Funding: No funding source to report for this review.

Acknowledgments: N/A.

Conflicts of Interest: The authors declare no conflict of interest.

\section{References}

1. Schwarz, D.A.; Katayama, C.D.; Hedrick, S.M. Schlafen, a New Family of Growth Regulatory Genes that Affect Thymocyte Development. Immunity 1998, 9, 657-668. [CrossRef]

2. Chen, J.; Kuhn, L.A. Deciphering the three-domain architecture in schlafens and the structures and roles of human schlafen12 and serpinB12 in transcriptional regulation. J. Mol. Graph. Model. 2019, 90, 59-76. [CrossRef]

3. Cohen-Tannoudji, M.; Vandormael-Pournin, S.; Le Bras, S.; Coumailleau, F.; Babinet, C.; Baldacci, P. A 2-Mb YAC/BAC-Based Physical Map of the Ovum Mutant (Om) Locus Region on Mouse Chromosome 11. Genomics 2000, 68, 273-282. [CrossRef] [PubMed]

4. Geserick, P.; Kaiser, F.; Klemm, U.; Kaufmann, S.H.E.; Zerrahn, J. Modulation of T cell development and activation by novel members of the Schlafen (slfn) gene family harbouring an RNA helicase-like motif. Int. Immunol. 2004, 16, 1535-1548. [CrossRef] [PubMed]

5. Bustos, O.; Naik, S.; Ayers, G.; Casola, C.; Perez-Lamigueiro, M.A.; Chippindale, P.T.; Pritham, E.J.; de la Casa-Esperón, E. Evolution of the Schlafen genes, a gene family associated with embryonic lethality, meiotic drive, immune processes and orthopoxvirus virulence. Gene 2009, 447, 1-11. [CrossRef] [PubMed]

6. Liu, F.; Zhou, P.; Wang, Q.; Zhang, M.; Li, D. The Schlafen family: Complex roles in different cell types and virus replication. Cell Biol. Int. 2018, 42, 2-8. [CrossRef] [PubMed]

7. De La Casa-Esperón, E. From mammals to viruses: The Schlafen genes in developmental, proliferative and immune processes. Biomol. Concepts 2011, 2, 159-169. [CrossRef] [PubMed]

8. Brady, G.; Boggan, L.; Bowie, A.; O'Neill, L. Schlafen-1 Causes a Cell Cycle Arrest by Inhibiting Induction of Cyclin D1. J. Biol. Chem. 2005, 280, 30723-30734. [CrossRef]

9. Kuang, C.-Y.; Yang, T.-H.; Zhang, Y.; Zhang, L.; Wu, Q. Schlafen 1 Inhibits the Proliferation and Tube Formation of Endothelial Progenitor Cells. PLoS ONE 2014, 9, e109711. [CrossRef]

10. Basson, M.D.; Wang, Q.; Chaturvedi, L.S.; Vomhof-DeKrey, E. Schlafen 12 Promotes Human Intestinal Epithelial Differentiation via Serpin B12 Modulation of the Deubiquitylation of Transcription Factors Such as CDX2. Gastroenterology 2018, 154, S180. [CrossRef]

11. Oh, P.-S.; Patel, V.B.; Sanders, M.A.; Kanwar, S.; Yu, Y.; Nautiyal, J.; Patel, B.B.; Majumdar, A.P.N. Schlafen-3 decreases cancer stem cell marker expression and autocrine/juxtacrine signaling in FOLFOX-resistant colon cancer cells. Am. J. Physiol. Liver Physiol. 2011, 301, G347-G355. [CrossRef]

12. Abdel-Mohsen, M.; Raposo, R.A.S.; Deng, X.; Li, M.; Liegler, T.; Sinclair, E.; Salama, M.S.; Ghanem, A.H.E.-D.; Hoh, R.; Wong, J.K.; et al. Expression profile of host restriction factors in HIV-1 elite controllers. Retrovirology 2013, 10, 106. [CrossRef] [PubMed]

13. Abdel-Mohsen, M.; Wang, C.; Strain, M.C.; Lada, S.M.; Deng, X.; Cockerham, L.R.; Pilcher, C.D.; Hecht, F.; Liegler, T.; Richman, D.D.; et al. Select host restriction factors are associated with HIV persistence during antiretroviral therapy. AIDS 2015, 29, 411-420. [CrossRef]

14. Al-Marsoummi, S.; Vomhof-DeKrey, E.; Basson, M.D. Schlafen12 Reduces the Aggressiveness of Triple Negative Breast Cancer through Post-Transcriptional Regulation of ZEB1 That Drives Stem Cell Differentiation. Cell. Physiol. Biochem. 2019, 53, 999-1014. [CrossRef] [PubMed]

15. Al-Marsoummi, S.; Pacella, J.; Dockter, K.; Soderberg, M.; Singhal, S.K.; Vomhof-DeKrey, E.E.; Basson, M.D. Schlafen 12 Is Prognostically Favorable and Reduces C-Myc and Proliferation in Lung Adenocarcinoma but Not in Lung Squamous Cell Carcinoma. Cancers 2020, 12, 2738. [CrossRef]

16. Nápoles, O.C.; Tsao, A.C.; Sanz-Anquela, J.M.; Sala, N.; Bonet, C.; Pardo, M.L.; Ding, L.; Simo, O.; Saqui-Salces, M.; Blanco, V.P.; et al. SCHLAFEN 5 expression correlates with intestinal metaplasia that progresses to gastric cancer. J. Gastroenterol. 2017, 52, 39-49. [CrossRef] [PubMed]

17. Isnaldi, E.; Ferraioli, D.; Ferrando, L.; Brohée, S.; Ferrando, F.; Fregatti, P.; Bedognetti, D.; Ballestrero, A.; Zoppoli, G. Schlafen-11 expression is associated with immune signatures and basal-like phenotype in breast cancer. Breast Cancer Res. Treat. 2019, 177, 335-343. [CrossRef] [PubMed]

18. Tian, L.; Song, S.; Liu, X.; Wang, Y.; Xu, X.; Hu, Y.; Xu, J. Schlafen-11 sensitizes colorectal carcinoma cells to irinotecan. Anti-Cancer Drugs 2014, 25, 1175-1181. [CrossRef]

19. Zoppoli, G.; Regairaz, M.; Leo, E.; Reinhold, W.C.; Varma, S.; Ballestrero, A.; Doroshow, J.H.; Pommier, Y. Putative DNA/RNA helicase Schlafen-11 (SLFN11) sensitizes cancer cells to DNA-damaging agents. Proc. Natl. Acad. Sci. USA 2012, 109, 15030-15035. [CrossRef] 
20. Barretina, J.; Caponigro, G.; Stransky, N.; Venkatesan, K.; Margolin, A.A.; Kim, S.; Wilson, C.J.; Lehár, J.; Kryukov, G.; Sonkin, D.; et al. The Cancer Cell Line Encyclopedia enables predictive modelling of anticancer drug sensitivity. Nature 2012, 483, 603-607. [CrossRef]

21. Nogales, V.; Reinhold, W.; Varma, S.; Cardus, A.M.; Moutinho, C.; Moran, S.; Heyn, H.; Sebio, A.; Barnadas, A.; Pommier, Y.; et al. Epigenetic inactivation of the putative DNA/RNA helicase SLFN11 in human cancer confers resistance to platinum drugs. Oncotarget 2016, 7, 3084-3097. [CrossRef] [PubMed]

22. He, T.; Zhang, M.; Zheng, R.; Zheng, S.; Linghu, E.; Herman, J.G.; Guo, M. Methylation ofSLFN11is a marker of poor prognosis and cisplatin resistance in colorectal cancer. Epigenomics 2017, 9, 849-862. [CrossRef]

23. Stewart, C.A.; Tong, P.; Cardnell, R.J.; Sen, T.; Li, L.; Gay, C.M.; Masrorpour, F.; Fan, Y.; Bara, R.O.; Feng, Y.; et al. Dynamic variations in epithelial-to-mesenchymal transition (EMT), ATM, and SLFN11 govern response to PARP inhibitors and cisplatin in small cell lung cancer. Oncotarget 2017, 8, 28575-28587. [CrossRef] [PubMed]

24. Protein BLAST: Search Protein Databases Using a Protein Query . Available online: https://blast.ncbi.nlm.nih.gov/Blast.cgi? PROGRAM=blastp\&PAGE_TYPE=BlastSearch\&LINK_LOC=blasthome (accessed on 27 July 2021).

25. Neumann, B.; Zhao, L.; Murphy, K.; Gonda, T.J. Subcellular localization of the Schlafen protein family. Biochem. Biophys. Res. Commun. 2008, 370, 62-66. [CrossRef]

26. Mavrommatis, E.; Fish, E.N.; Platanias, L.C. The Schlafen Family of Proteins and Their Regulation by Interferons. J. Interf. Cytokine Res. 2013, 33, 206-210. [CrossRef] [PubMed]

27. Yang, J.-Y.; Deng, X.-Y.; Li, Y.-S.; Ma, X.; Feng, J.-X.; Yu, B.; Chen, Y.; Luo, Y.-L.; Wang, X.; Chen, M.-L.; et al. Structure of Schlafen13 reveals a new class of tRNA/rRNA- targeting RNase engaged in translational control. Nat. Commun. 2018, 9, 1-13. [CrossRef]

28. Chaturvedi, L.; Sun, K.; Walsh, M.F.; Kuhn, L.A.; Basson, M.D. The P-loop region of Schlafen 3 acts within the cytosol to induce differentiation of human Caco-2 intestinal epithelial cells. Biochim. Biophys. Acta Bioenerg. 2014, 1843, 3029-3037. [CrossRef] [PubMed]

29. Basson, M.D.; Wang, Q.; Chaturvedi, L.S.; More, S.; Vomhof-DeKrey, E.E.; Al-Marsoummi, S.; Sun, K.; Kuhn, L.A.; Kovalenko, P.; Kiupel, M. Schlafen 12 Interaction with Serpin B12 and Deubiquitylases Drives Human Enterocyte Differentiation. Cell. Physiol. Biochem. 2018, 48, 1274-1290. [CrossRef]

30. Li, M.; Kao, E.; Gao, X.; Sandig, H.; Limmer, K.; Pavon-Eternod, M.; Jones, T.E.; Landry, S.; Pan, T.; Weitzman, M.D.; et al. Codon-usage-based inhibition of HIV protein synthesis by human schlafen 11. Nature 2012, 491, 125-128. [CrossRef]

31. Valdez, F.; Salvador, J.; Palermo, P.M.; Mohl, J.; Hanley, K.; Watts, D.; Llano, M. Schlafen 11 Restricts Flavivirus Replication. J. Virol. 2019, 93. [CrossRef]

32. Lee, N.K.; Choi, H.K.; Yoo, H.J.; Shin, J.; Lee, S.Y. RANKL-induced schlafen2 is a positive regulator of osteoclastogenesis. Cell. Signal. 2008, 20, 2302-2308. [CrossRef] [PubMed]

33. Omar, I.; Guterman-Ram, G.; Rahat, D.; Tabach, Y.; Berger, M.; Levaot, N. Schlafen2 mutation in mice causes an osteopetrotic phenotype due to a decrease in the number of osteoclast progenitors. Sci. Rep. 2018, 8, 13005. [CrossRef] [PubMed]

34. Kovalenko, P.L.; Yuan, L.; Sun, K.; Kunovska, L.; Seregin, S.; Amalfitano, A.; Basson, M.D. Regulation of Epithelial Differentiation in Rat Intestine by Intraluminal Delivery of an Adenoviral Vector or Silencing RNA Coding for Schlafen 3. PLoS ONE 2013, 8, e79745. [CrossRef]

35. Mavrommatis, E.; Arslan, A.D.; Sassano, A.; Hua, Y.; Kroczynska, B.; Platanias, L.C. Expression and Regulatory Effects of Murine Schlafen (Slfn) Genes in Malignant Melanoma and Renal Cell Carcinoma. J. Biol. Chem. 2013, 288, 33006-33015. [CrossRef] [PubMed]

36. Lund, S.; Christensen, K.V.; Hedtjärn, M.; Mortensen, A.L.; Hagberg, H.; Falsig, J.; Hasseldam, H.; Schrattenholz, A.; Pörzgen, P.; Leist, M. The dynamics of the LPS triggered inflammatory response of murine microglia under different culture and in vivo conditions. J. Neuroimmunol. 2006, 180, 71-87. [CrossRef] [PubMed]

37. Katsoulidis, E.; Carayol, N.; Woodard, J.; Konieczna, I.; Majchrzak-Kita, B.; Jordan, A.; Sassano, A.; Eklund, E.A.; Fish, E.N.; Platanias, L.C. Role of Schlafen 2 (SLFN2) in the Generation of Interferon $\alpha$-induced Growth Inhibitory Responses. J. Biol. Chem. 2009, 284, 25051-25064. [CrossRef] [PubMed]

38. Berger, M.; Krebs, P.; Crozat, K.; Li, X.; Croker, B.; Siggs, O.; Popkin, D.; Du, X.; Lawson, B.R.; Theofilopoulos, A.N.; et al. An Slfn2 mutation causes lymphoid and myeloid immunodeficiency due to loss of immune cell quiescence. Nat. Immunol. 2010, 11, 335-343. [CrossRef]

39. Omar, I.; Lapenna, A.; Cohen-Daniel, L.; Tirosh, B.; Berger, M. Schlafen 2 mutation unravels a role for chronic ER stress in the loss of T cell quiescence. Oncotarget 2016, 7, 39396-39407. [CrossRef] [PubMed]

40. Omar, I.; Rom, O.; Aviram, M.; Cohen-Daniel, L.; Gebre, A.K.; Parks, J.S.; Berger, M. Slfn2 mutation-induced loss of T-cell quiescence leads to elevated de novo sterol synthesis. Immunology 2017, 152, 484-493. [CrossRef] [PubMed]

41. Sohn, W.-J.; Kim, D.; Lee, K.-W.; Kim, M.-S.; Kwon, S.; Lee, Y.; Kim, O.-S.; Kwon, H.-J. Novel transcriptional regulation of the schlafen-2 gene in macrophages in response to TLR-triggered stimulation. Mol. Immunol. 2007, 44, 3273-3282. [CrossRef]

42. Condamine, T.; LE Luduec, J.-B.; Chiffoleau, E.; Bériou, G.; Louvet, C.; Heslan, M.; Tilly, G.; Cuturi, M.-C. Characterization of Schlafen-3 expression in effector and regulatory T cells. J. Leukoc. Biol. 2010, 87, 451-456. [CrossRef] [PubMed]

43. Yuan, L.; Yu, Y.; Sanders, M.A.; Majumdar, A.P.N.; Basson, M.D. Schlafen 3 induction by cyclic strain regulates intestinal epithelial differentiation. Am. J. Physiol. Liver Physiol. 2010, 298, G994-G1003. [CrossRef] 
44. Walsh, M.F.; Hermann, R.; Lee, J.H.; Chaturvedi, L.; Basson, M.D. Schlafen 3 Mediates the Differentiating Effects of Cdx2 in Rat IEC-Cdx2L1 Enterocytes. J. Investig. Surg. 2015, 28, 202-207. [CrossRef] [PubMed]

45. Patel, B.B.; Yu, Y.; Du, J.; Rishi, A.K.; Sarkar, F.H.; Tarca, A.L.; Wali, A.; Majumdar, A.P.N. Schlafen 3, a novel gene, regulates colonic mucosal growth during aging. Am. J. Physiol. Liver Physiol. 2009, 296, G955-G962. [CrossRef] [PubMed]

46. Vomhof-DeKrey, E.E.; Lee, J.; Lansing, J.; Brown, C.; Darland, D.; Basson, M.D. Schlafen 3 knockout mice display gender-specific differences in weight gain, food efficiency, and expression of markers of intestinal epithelial differentiation, metabolism, and immune cell function. PLoS ONE 2019, 14, e0219267. [CrossRef] [PubMed]

47. Van Zuylen, W.J.; Garceau, V.; Idris, A.; Schroder, K.; Irvine, K.M.; Lattin, J.E.; Ovchinnikov, D.A.; Perkins, A.C.; Cook, A.D.; Hamilton, J.A.; et al. Macrophage Activation and Differentiation Signals Regulate Schlafen-4 Gene Expression: Evidence for Schlafen-4 as a Modulator of Myelopoiesis. PLoS ONE 2011, 6, e15723. [CrossRef]

48. El-Zaatari, M.; Kao, J.Y.; Tessier, A.; Bai, L.; Hayes, M.M.; Fontaine, C.; Eaton, K.A.; Merchant, J.L. Gli1 Deletion Prevents Helicobacter-Induced Gastric Metaplasia and Expansion of Myeloid Cell Subsets. PLoS ONE 2013, 8, e58935. [CrossRef]

49. Ding, L.; Hayes, M.M.; Photenhauer, A.; Eaton, K.A.; Li, Q.; Ocadiz-Ruiz, J.R.; Merchant, J.L. Schlafen 4-Expressing myeloidderived suppressor cells are induced during murine gastric metaplasia. J. Clin. Investig. 2016, 126, 2867-2880. [CrossRef]

50. Nakagawa, K.; Matsuki, T.; Zhao, L.; Kuniyoshi, K.; Tanaka, H.; Ebina, I.; Yoshida, K.J.; Nabeshima, H.; Fukushima, K.; Kanemaru, H.; et al. Schlafen-8 is essential for lymphatic endothelial cell activation in experimental autoimmune encephalomyelitis. Int. Immunol. 2018, 30, 69-78. [CrossRef]

51. Puck, A.; Aigner, R.; Modak, M.; Cejka, P.; Blaas, D.; Stöckl, J. Expression and regulation of Schlafen (SLFN) family members in primary human monocytes, monocyte-derived dendritic cells and T cells. Results Immunol. 2015, 5, 23-32. [CrossRef]

52. Arslan, A.D.; Sassano, A.; Saleiro, D.; Lisowski, P.; Kosciuczuk, E.M.; Fischietti, M.; Eckerdt, F.; Fish, E.N.; Platanias, L.C. Human SLFN5 is a transcriptional co-repressor of STAT1-mediated interferon responses and promotes the malignant phenotype in glioblastoma. Oncogene 2017, 36, 6006-6019. [CrossRef]

53. Yatim, A.; Benne, C.; Sobhian, B.; Laurent-Chabalier, S.; Deas, O.; Judde, J.-G.; Lelievre, J.-D.; Levy, Y.; Benkirane, M. NOTCH1 Nuclear Interactome Reveals Key Regulators of Its Transcriptional Activity and Oncogenic Function. Mol. Cell 2012, 48, 445-458. [CrossRef]

54. Lin, Y.-Z.; Sun, L.-K.; Zhu, D.-T.; Hu, Z.; Wang, X.-F.; Du, C.; Wang, Y.-H.; Wang, X.-J.; Zhou, J.-H. Equine schlafen 11 restricts the production of equine infectious anemia virus via a codon usage-dependent mechanism. Virology 2016, 495, 112-121. [CrossRef] [PubMed]

55. Moribe, F.; Nishikori, M.; Takashima, T.; Taniyama, D.; Onishi, N.; Arima, H.; Sasanuma, H.; Akagawa, R.; Elloumi, F.; Takeda, S.; et al. Epigenetic suppression of SLFN11 in germinal center B-cells during B-cell development. PLoS ONE 2021, 16, e0237554. [CrossRef] [PubMed]

56. Puck, A.; Hopf, S.; Modak, M.; Majdic, O.; Cejka, P.; Blüml, S.; Schmetterer, K.; Arnold-Schrauf, C.; Gerwien, J.G.; Frederiksen, K.S.; et al. The soluble cytoplasmic tail of CD45 (ct-CD45) in human plasma contributes to keep T cells in a quiescent state. Eur. J. Immunol. 2017, 47, 193-205. [CrossRef]

57. Seong, R.-K.; Seo, S.-W.; Kim, J.-A.; Fletcher, S.J.; Morgan, N.; Kumar, M.; Choi, Y.-K.; Shin, O.S. Schlafen 14 (SLFN14) is a novel antiviral factor involved in the control of viral replication. Immunobiology 2017, 222, 979-988. [CrossRef] [PubMed]

58. Marconi, C.; Di Buduo, C.A.; Barozzi, S.; Palombo, F.; Pardini, S.; Zaninetti, C.; Pippucci, T.; Noris, P.; Balduini, A.; Seri, M.; et al. SLFN14-related thrombocytopenia: Identification within a large series of patients with inherited thrombocytopenia. Thromb. Haemost. 2016, 115, 1076-1079. [CrossRef]

59. Pisareva, V.P.; Muslimov, I.A.; Tcherepanov, A.; Pisarev, A.V. Characterization of Novel Ribosome-Associated Endoribonuclease SLFN14 from Rabbit Reticulocytes. Biochemistry 2015, 54, 3286-3301. [CrossRef]

60. Fletcher, S.J.; Johnson, B.; Lowe, G.C.; Bem, D.; Drake, S.; Lordkipanidze, M.; Guiú, I.S.; Dawood, B.; Rivera, J.; Simpson, M.A.; et al. SLFN14 mutations underlie thrombocytopenia with excessive bleeding and platelet secretion defects. J. Clin. Investig. 2015, 125, 3600-3605. [CrossRef] [PubMed]

61. Gubse, C.; Goodbody, R.; Ecker, A.; Brady, G.; O’Neill, L.; Jacobs, N.; Smith, G.L. Camelpox virus encodes a schlafen-like protein that affects orthopoxvirus virulence. J. Gen. Virol. 2007, 88, 1667-1676. [CrossRef]

62. Katsoulidis, E.; Mavrommatis, E.; Woodard, J.; Shields, M.A.; Sassano, A.; Carayol, N.; Sawicki, K.T.; Munshi, H.G.; Platanias, L.C. Role of interferon $\alpha$ (IFN $\alpha$ )-inducible Schlafen-5 in regulation of anchorage-independent growth and invasion of malignant melanoma cells. J. Biol. Chem. 2010, 285, 40333-40341. [CrossRef] [PubMed]

63. Sassano, A.; Mavrommatis, E.; Arslan, A.D.; Kroczynska, B.; Beauchamp, E.M.; Khuon, S.; Chew, T.-L.; Green, K.J.; Munshi, H.G.; Verma, A.K.; et al. Human Schlafen 5 (SLFN5) Is a Regulator of Motility and Invasiveness of Renal Cell Carcinoma Cells. Mol. Cell. Biol. 2015, 35, 2684-2698. [CrossRef]

64. Takashima, T.; Sakamoto, N.; Murai, J.; Taniyama, D.; Honma, R.; Ukai, S.; Maruyama, R.; Kuraoka, K.; Rajapakse, V.N.; Pommier, Y.; et al. Immunohistochemical analysis of SLFN11 expression uncovers potential non-responders to DNA-damaging agents overlooked by tissue RNA-seq. Virchows Arch. 2021, 478, 569-579. [CrossRef] [PubMed]

65. Takashima, T.; Taniyama, D.; Sakamoto, N.; Yasumoto, M.; Asai, R.; Hattori, T.; Honma, R.; Thang, P.Q.; Ukai, S.; Maruyama, R.; et al. Schlafen 11 predicts response to platinum-based chemotherapy in gastric cancers. Br. J. Cancer 2021. [CrossRef] [PubMed]

66. Yang, X.; Peng, R.; Peng, H.; Zhang, Q.; Long, G.; Wu, G.; Liang, Z. The association between SLFN5 expression and the prognosis of non-small cell lung cancer. Int. J. Clin. Exp. Med. 2019, 12, 682-689. 
67. Shee, K.; Wells, J.D.; Jiang, A.; Miller, T.W. Integrated pan-cancer gene expression and drug sensitivity analysis reveals SLFN11 mRNA as a solid tumor biomarker predictive of sensitivity to DNA-damaging chemotherapy. PLoS One 2019, 14, e0224267. [CrossRef] [PubMed]

68. Martinez, R.S.; Salji, M.J.; Rushworth, L.; Ntala, C.; Rodriguez Blanco, G.; Hedley, A.; Clark, W.; Peixoto, P.; Hervouet, E.; Renaude, E.; et al. SLFN5 regulates LAT1-mediated mTOR activation in castration-resistant prostate cancer. Cancer Res. 2021. [CrossRef]

69. Conteduca, V.; Ku, S.-Y.; Puca, L.; Slade, M.; Fernandez, L.; Hess, J.; Bareja, R.; Vlachostergios, P.J.; Sigouros, M.; Mosquera, J.M.; et al. SLFN11 Expression in Advanced Prostate Cancer and Response to Platinum-based Chemotherapy. Mol. Cancer Ther. 2020, 19, 1157-1164. [CrossRef]

70. Peng, H.; Yang, M.; Xu, X.M.; She, S.; Ran, X.P.; Li, S.Y.; Hu, H.D.; Ren, H.; Hu, P. Decreased expression of schlafen5 (SLFN5) correlates with unfavorable survival in human hepatocellular carcinoma. Int. J. Clin. Exp. Pathol. 2016, 9, 7014-7096.

71. Zhou, C.; Liu, C.; Liu, W.; Chen, W.; Yin, Y.; Li, C.-W.; Hsu, J.L.; Sun, J.; Zhou, Q.; Li, H.; et al. SLFN11 inhibits hepatocellular carcinoma tumorigenesis and metastasis by targeting RPS4X via mTOR pathway. Theranostics 2020, 10, 4627-4643. [CrossRef]

72. Kagami, T.; Yamade, M.; Suzuki, T.; Uotani, T.; Tani, S.; Hamaya, Y.; Iwaizumi, M.; Osawa, S.; Sugimoto, K.; Miyajima, H.; et al. The first evidence for SLFN11 expression as an independent prognostic factor for patients with esophageal cancer after chemoradiotherapy. BMC Cancer 2020, 20, 1123. [CrossRef]

73. Wan, G.; Zhu, J.; Gu, X.; Yang, Y.; Liu, Y.; Wang, Z.; Zhao, Y.; Wu, H.; Huang, G.; Lu, C. Human Schlafen 5 regulates reversible epithelial and mesenchymal transitions in breast cancer by suppression of ZEB1 transcription. Br. J. Cancer 2020, 123, 633-643. [CrossRef] [PubMed]

74. Gu, X.; Wan, G.; Yang, Y.; Liu, Y.; Yang, X.; Zheng, Y.; Jiang, L. SLFN5 influences proliferation and apoptosis by upregulating PTEN transcription via ZEB1 and inhibits the purine metabolic pathway in breast cancer. Am. J. Cancer Res. 2020, 10, 2832-2850. [PubMed]

75. Bartha, Á.; Győrffy, B. TNMplot.com: A Web Tool for the Comparison of Gene Expression in Normal, Tumor and Metastatic Tissues. Int. J. Mol. Sci. 2021, 22, 1-12. [CrossRef] [PubMed]

76. Guo, L.; Liu, Z.; Tang, X. Overexpression of SLFN5 induced the epithelial-mesenchymal transition in human lung cancer cell line A549 through $\beta$-catenin/Snail/E-cadherin pathway. Eur. J. Pharmacol. 2019, 862, 172630. [CrossRef]

77. Wan, G.; Liu, Y.; Zhu, J.; Guo, L.; Li, C.; Yang, Y.; Gu, X.; Deng, L.-L.; Lu, C. SLFN5 suppresses cancer cell migration and invasion by inhibiting MT1-MMP expression via AKT/GSK-3 $\beta / \beta$-catenin pathway. Cell. Signal. 2019, 59, 1-12. [CrossRef]

78. Mu, Y.; Lou, J.; Srivastava, M.; Zhao, B.; Feng, X.; Liu, T.; Chen, J.; Huang, J. SLFN11 inhibits checkpoint maintenance and homologous recombination repair. EMBO Rep. 2016, 17, 94-109. [CrossRef]

79. Li, M.; Kao, E.; Malone, D.; Gao, X.; Wang, J.Y.J.; David, M. DNA damage-induced cell death relies on SLFN11-dependent cleavage of distinct type II tRNAs. Nat. Struct. Mol. Biol. 2018, 25, 1047-1058. [CrossRef]

80. Jo, U.; Murai, Y.; Chakka, S.; Chen, L.; Cheng, K.; Murai, J.; Saha, L.K.; Miller Jenkins, L.M.; Pommier, Y. SLFN11 promotes CDT1 degradation by CUL4 in response to replicative DNA damage, while its absence leads to synthetic lethality with ATR/CHK1 inhibitors. Proc. Natl. Acad. Sci. USA 2021, 118, e2015654118. [CrossRef]

81. Murai, J.; Zhang, H.; Pongor, L.; Tang, S.W.; Jo, U.; Moribe, F.; Ma, Y.; Tomita, M.; Pommier, Y. Chromatin Remodeling and Immediate Early Gene Activation by SLFN11 in Response to Replication Stress. Cell Rep. 2020, 30, 4137-4151. [CrossRef] [PubMed]

82. Murai, J.; Tang, S.W.; Leo, E.; Baechler, S.A.; Redon, C.E.; Zhang, H.; Al Abo, M.; Rajapakse, V.N.; Nakamura, E.; Jenkins, L.M.M.; et al. SLFN11 Blocks Stressed Replication Forks Independently of ATR. Mol. Cell 2018, 69, 371-384. [CrossRef]

83. Li, D.; Chen, J.; Ai, Y.; Gu, X.; Li, L.; Che, D.; Jiang, Z.; Li, L.; Chen, S.; Huang, H.; et al. Estrogen-Related Hormones Induce Apoptosis by Stabilizing Schlafen-12 Protein Turnover. Mol. Cell 2019, 75, 1103-1116. [CrossRef]

84. Garvie, C.W.; Wu, X.; Papanastasiou, M.; Lee, S.; Fuller, J.; Schnitzler, G.R.; Horner, S.W.; Baker, A.; Zhang, T.; Mullahoo, J.P.; et al. Structure of PDE3A-SLFN12 complex reveals requirements for activation of SLFN12 RNase. Nat. Commun. 2021, 12, 4375. [CrossRef] [PubMed]

85. Merchant, J.L.; Ding, L. Hedgehog Signaling Links Chronic Inflammation to Gastric Cancer Precursor Lesions. Cell. Mol. Gastroenterol. Hepatol. 2017, 3, 201-210. [CrossRef] [PubMed]

86. Kaur, S.; Schwartz, A.L.; Jordan, D.G.; Soto-Pantoja, D.R.; Kuo, B.; Elkahloun, A.G.; Mathews Griner, L.; Thomas, C.J.; Ferrer, M.; Thomas, A.; et al. Identification of Schlafen-11 as a Target of CD47 Signaling That Regulates Sensitivity to Ionizing Radiation and Topoisomerase Inhibitors. Front. Oncol. 2019, 9, 994. [CrossRef] [PubMed]

87. van der Voort van Zijp, J.; Hoekstra, H.J.; Basson, M.D. Evolving management of colorectal cancer. World J. Gastroenterol. 2008, 14, 3956-3967. [CrossRef]

88. El Bali, M.; Bakkach, J.; Bennani Mechita, M. Colorectal Cancer: From Genetic Landscape to Targeted Therapy. J. Oncol. 2021, 2021, 9918116. [CrossRef]

89. Vomhof-DeKrey, E.E.; Umthun, J.; Basson, M.D. Loss of Schlafen3 influences the expression levels of Schlafen family members in ileum, thymus, and spleen tissue. PeerJ 2020, 2020. [CrossRef]

90. Lima, T.S.; Iglesias-Gato, D.; Souza, L.D.O.; Stenvang, J.; Lima, D.S.; Røder, M.A.; Brasso, K.; Moreira, J.M.A. Molecular Profiling of Docetaxel-Resistant Prostate Cancer Cells Identifies Multiple Mechanisms of Therapeutic Resistance. Cancers (Basel). 2021, 13, 1290. [CrossRef] 
91. Zavridou, M.; Strati, A.; Bournakis, E.; Smilkou, S.; Tserpeli, V.; Lianidou, E. Prognostic Significance of Gene Expression and DNA Methylation Markers in Circulating Tumor Cells and Paired Plasma Derived Exosomes in Metastatic Castration Resistant Prostate Cancer. Cancers (Basel). 2021, 13, 780. [CrossRef]

92. Kovalenko, P.L.; Basson, M.D. Schlafen 12 expression modulates prostate cancer cell differentiation. J. Surg. Res. 2014, 190, 177-184. [CrossRef]

93. Yersal, S.B.O. Biological subtypes of breast cancer: Prognostic and therapeutic implications. World J. Clin. Oncol. 2014, 5, 412-424. [CrossRef] [PubMed]

94. Winkler, C.; Armenia, J.; Jones, G.N.; Tobalina, L.; Sale, M.J.; Petreus, T.; Baird, T.; Serra, V.; Wang, A.T.; Lau, A.; et al. SLFN11 informs on standard of care and novel treatments in a wide range of cancer models. Br. J. Cancer 2021, 124, 951-962. [CrossRef] [PubMed]

95. Zhang, F.; Cui, Y. Dysregulation of DNA methylation patterns may identify patients with breast cancer resistant to endocrine therapy: A predictive classifier based on differentially methylated regions. Oncol. Lett. 2019, 18, 1287-1303. [CrossRef] [PubMed]

96. Goldshtein, A.; Zerbib, S.M.; Omar, I.; Cohen-Daniel, L.; Popkin, D.; Berger, M. Loss of T-cell quiescence by targeting Slfn2 prevents the development and progression of T-ALL. Oncotarget 2016, 7, 46835-46847. [CrossRef]

97. Andersson, E.; Eldfors, S.; Edgren, H.; Ellonen, P.; Väkevä, L.; Ranki, A.; Mustjoki, S. Novel TBL1XR1, EPHA7 and SLFN12 mutations in a Sezary syndrome patient discovered by whole exome sequencing. Exp. Dermatol. 2014, 23, 366-368. [CrossRef] [PubMed]

98. Mezzadra, R.; de Bruijn, M.; Jae, L.; Gomez-Eerland, R.; Duursma, A.; Scheeren, F.A.; Brummelkamp, T.R.; Schumacher, T.N. SLFN11 can sensitize tumor cells towards IFN- $\gamma$-mediated T cell killing. PLoS ONE 2019, 14, e0212053. [CrossRef]

99. Aricò, E.; Castiello, L.; Capone, I.; Gabriele, L.; Belardelli, F. Type I Interferons and Cancer: An Evolving Story Demanding Novel Clinical Applications. Cancers 2019, 11, 1943. [CrossRef]

100. Ningrum, R.A. Human Interferon Alpha-2b: A Therapeutic Protein for Cancer Treatment. Scientifica 2014, 2014, 1-8. [CrossRef] [PubMed]

101. Murai, J.; Feng, Y.; Yu, G.K.; Ru, Y.; Tang, S.-W.; Shen, Y.; Pommier, Y. Resistance to PARP inhibitors by SLFN11 inactivation can be overcome by ATR inhibition. Oncotarget 2016, 7, 76534-76550. [CrossRef]

102. Rathkey, D.; Khanal, M.; Murai, J.; Zhang, J.; Sengupta, M.; Jiang, Q.; Morrow, B.; Evans, C.N.; Chari, R.; Fetsch, P.; et al. Sensitivity of Mesothelioma Cells to PARP Inhibitors Is Not Dependent on BAP1 but Is Enhanced by Temozolomide in Cells with High-Schlafen 11 and Low-O6-methylguanine-DNA Methyltransferase Expression. J. Thorac. Oncol. 2020, 15, 843-859. [CrossRef] [PubMed]

103. Lok, B.; Gardner, E.; Schneeberger, V.E.; Ni, A.; Desmeules, P.; Rekhtman, N.; De Stanchina, E.; Teicher, B.A.; Riaz, N.; Powell, S.N.; et al. PARP Inhibitor Activity Correlates with SLFN11 Expression and Demonstrates Synergy with Temozolomide in Small Cell Lung Cancer. Clin. Cancer Res. 2017, 23, 523-535. [CrossRef]

104. Inno, A.; Stagno, A.; Gori, S. Schlafen-11 (SLFN11): A step forward towards personalized medicine in small-cell lung cancer? Transl. Lung Cancer Res. 2018, 7, S341-S345. [CrossRef] [PubMed]

105. Serzan, M.T.; Farid, S.; Liu, S.V. Drugs in development for small cell lung cancer. J. Thorac. Dis. 2020, 12, 6298-6307. [CrossRef]

106. Van Erp, A.E.M.; van Houdt, L.; Hillebrandt-Roeffen, M.H.S.; van Bree, N.F.H.N.; Flucke, U.E.; Mentzel, T.; Shipley, J.; Desar, I.M.E.; Fleuren, E.D.G.; Versleijen-Jonkers, Y.M.H.; et al. Olaparib and temozolomide in desmoplastic small round cell tumors: A promising combination in vitro and in vivo. J. Cancer Res. Clin. Oncol. 2020, 146, 1659-1670. [CrossRef]

107. Tlemsani, C.; Pongor, L.; Elloumi, F.; Girard, L.; Huffman, K.E.; Roper, N.; Varma, S.; Luna, A.; Rajapakse, V.N.; Sebastian, R.; et al. SCLC-CellMiner: A Resource for Small Cell Lung Cancer Cell Line Genomics and Pharmacology Based on Genomic Signatures. Cell Rep. 2020, 33, 108296. [CrossRef]

108. Tang, S.-W.; Thomas, A.; Murai, J.; Trepel, J.B.; Bates, S.E.; Rajapakse, V.N.; Pommier, Y. Overcoming Resistance to DNA-Targeted Agents by Epigenetic Activation of Schlafen 11 (SLFN11) Expression with Class I Histone Deacetylase Inhibitors. Clin. Cancer Res. 2018, 24, 1944-1953. [CrossRef] [PubMed]

109. Iwasaki, J.; Komori, T.; Nakagawa, F.; Nagase, H.; Uchida, J.; Matsuo, K.; Uto, Y. Schlafen11 Expression Is Associated with the Antitumor Activity of Trabectedin in Human Sarcoma Cell Lines. Anticancer. Res. 2019, 39, 3553-3563. [CrossRef] [PubMed]

110. Coussy, F.; El-Botty, R.; Château-Joubert, S.; Dahmani, A.; Montaudon, E.; Leboucher, S.; Morisset, L.; Painsec, P.; Sourd, L.; Huguet, L.; et al. BRCAness, SLFN11, and RB1 loss predict response to topoisomerase I inhibitors in triple-negative breast cancers. Sci. Transl. Med. 2020, 12, eaax2625. [CrossRef]

111. Marzi, L.; Szabova, L.; Gordon, M.; Ohler, Z.W.; Sharan, S.K.; Beshiri, M.; Etemadi, M.; Murai, J.; Kelly, K.; Pommier, Y. The Indenoisoquinoline TOP1 Inhibitors Selectively Target Homologous Recombination-Deficient and Schlafen 11-Positive Cancer Cells and Synergize with Olaparib. Clin. Cancer Res. 2019, 25, 6206-6216. [CrossRef] [PubMed]

112. Mao, S.; Chaerkady, R.; Yu, W.; D’Angelo, G.; Garcia, A.; Chen, H.; Barrett, A.M.; Phipps, S.; Fleming, R.; Hess, S.; et al. Resistance to Pyrrolobenzodiazepine Dimers Is Associated with SLFN11 Downregulation and Can Be Reversed through Inhibition of ATR. Mol. Cancer Ther. 2021, 20, 541-552. [CrossRef]

113. Lewis, T.A.; De Waal, L.; Wu, X.; Ellerman, M.; Kopitz, C.; Wengner, A.; Eis, K.; Lange, M.; Tersteegen, A.; Lienau, P.; et al. Abstract 5880: Small-molecule modulators of PDE3/SLFN12 to kill cancer cells. Cancer Res. 2018, 78, 5880. [CrossRef] 
114. De Waal, L.; Lewis, T.; Rees, M.G.; Tsherniak, A.; Wu, X.; Choi, P.; Gechijian, L.; Hartigan, C.; Faloon, P.W.; Hickey, M.J.; et al. Identification of cancer-cytotoxic modulators of PDE3A by predictive chemogenomics. Nat. Chem. Biol. 2016, 12, 102-108. [CrossRef] [PubMed]

115. Lewis, T.A.; De Waal, L.; Wu, X.; Youngsaye, W.; Wengner, A.; Kopitz, C.; Lange, M.; Gradl, S.; Ellermann, M.; Lienau, P.; et al. Optimization of PDE3A Modulators for SLFN12-Dependent Cancer Cell Killing. ACS Med. Chem. Lett. 2019, 10, 1537-1542. [CrossRef] [PubMed]

116. Nazir, M.; Senkowski, W.; Nyberg, F.; Blom, K.; Edqvist, P.-H.; Jarvius, M.; Andersson, C.; Gustafsson, M.G.; Nygren, P.; Larsson, R.; et al. Targeting tumor cells based on Phosphodiesterase 3A expression. Exp. Cell Res. 2017, 361, 308-315. [CrossRef]

117. Ai, Y.; He, H.; Chen, P.; Yan, B.; Zhang, W.; Ding, Z.; Li, D.; Chen, J.; Ma, Y.; Cao, Y.; et al. An alkaloid initiates phosphodiesterase 3A-schlafen 12 dependent apoptosis without affecting the phosphodiesterase activity. Nat. Commun. 2020, 11, 1-10. [CrossRef] [PubMed]

118. Wu, X.; Schnitzler, G.R.; Gao, G.F.; Diamond, B.; Baker, A.R.; Kaplan, B.; Williamson, K.; Westlake, L.; Lorrey, S.; Lewis, T.A.; et al. Mechanistic insights into cancer cell killing through interaction of phosphodiesterase 3A and schlafen family member 12 . J. Biol. Chem. 2020, 295, 3431-3446. [CrossRef] [PubMed] 